\title{
Spray Behaviour and Particulate Matter Emissions with M15 Methanol/Gasoline Blends in a GDI Engine
}

\author{
Safwan Hanis Mohd Murad, Joseph Camm, Richard Stone, \\ Martin Davy \\ Department of Engineering Science, University of Oxford, Oxford, UK. \\ Dave Richardson \\ Powertrain Research and Technology, Jaguar Land Rover, Coventry, UK.
}

\begin{abstract}
Model M15 gasoline fuels have been created from pure fuel components, to give independent control of volatility, the heavy end content and the aromatic content, in order to understand the effect of the fuel properties on Gasoline Direct Injection (GDI) fuel spray behaviour and the subsequent particulate number emissions. Each fuel was imaged at a range of fuel temperatures in a spray rig and in a motored optical engine, to cover the full range from non-flas hing sprays through to flare flashing sprays. The spray axial penetration (and potential piston and liner impingement), and spray evaporation rate were extracted from the images.
\end{abstract}

Firing engine tests with the fuels with the same fuel temperatures were performed and exhaust particulate number spectra captured using a DMS500 Mark II Particle Spectrometer. Data from the spray images and knowledge of the fuel evaporative performance has been used to explain some of the observed findings that might appear to be against the expected trends, but can be explained in terms of the saturation pressure ratio the ratio of the fuel vapour pressure to the system pressure.

\section{INTRODUCTION}

\section{Motivation}

Particulate matter (PM) emissions from internal combustion engines are one of the many big challenges for vehicle manufacturers to overcome. Environmental and health enforcers require the automotive industry to comply with new stringent emission requirements. It is reported that in Europe, over $90 \%$ of the population is estimated to be exposed to levels of particulate pollution that represents a risk to health, and about a third of all European citizens are exposed to levels of particulate pollution above EU permitted levels for air quality in Europe 2014 [1].

Gasoline containing a low proportion of methanol (less than $50 \%$ by volume) is a popular fuel in certain areas where there is a local source for

Page 1 of 18 methanol production, for example methanol from coal or methanol from captured $\mathrm{CO}_{2}$ [2][3]. These types of fuel have been subject to conflicting reports in the literature over the contribution to engine out $\mathrm{PM}$, and unusual results have been found that cannot easily be explained.

\section{GDI challenges}

The main challenge for a fuel injection system in a GDI engine operating in a homogeneous mode is to achieve a homogeneous air-fuel mixture in the cylinder, within a specific time window, from the start of fuel injection to spark ignition. Injection timing variations are constrained by piston crown and cylinder liner impingement, and the time available for evaporation and mixing of the air and fuel. Currently, the preparation of air-fuel mixtures for GDI engines is worse than that of Port Fuel Injection (PFI) engines, as evidenced by their higher PM emissions for most conditions [4]. The common problems reported by many researchers were fuel impingement on cylinder surfaces, incomplete droplet evaporation and also heterogeneous mixtures. These problems are being tackled by numerous methods such as: multiple injections to reduce spray penetration, increasing injection pressure with a smaller nozzle hole so as to reduce spray droplet diameters, and even modification to the injector nozzle to target spray into a specific area [5] [6].

In a Spark Ignition (SI) engine, fuel is normally injected in a higher quantity during cold start conditions. This is to counter the poor performance of fuel evaporation at low temperature, and this was found to be worse in a GDI engine. During opening of the throttle, the pressure in the cylinder rises and the partial pressure of the evaporated fuel rises, this slows droplet evaporation and leaves fuel rich zones that during combustion contribute to PM formation [7]. If the partial pressure of the fuel rises above the saturation pressure, then fuel can condense during throttle-opening pressure transients. Certain operating conditions, lead to fuel impingement on the cylinder wall or piston surface creating a fuel film. Some of the fuel film evaporates while some might survive the vigorous charge motion or the high combustion 
temperatures. These films produce fuel rich regions and cause pool fires when subjected to flame fronts which later produce PM [8].

\section{Fuel effects}

In GDI engines, while many factors contribute to the emission of PM, the fundamental concept for reducing its production is by having a homogeneous air fuel mixture. A homogeneous mixture gives a stable global air-fuel ratio, and the fuel properties can play a part in achieving this. The distillation range of the fuel and its composition does impact on the evaporation process and consequently the global air-fuel ratio and homogeneity. The most important factor towards PM production would be the heavy end of the fuel, which has the highest molar mass and is the least volatile component [10]. A report by the U.S. Environmental Protection Agency, 2013, showed that there were correlations between the T90 and T50 temperatures of gasoline with the PM emissions when tested on PFI engines. Correlation with GDI engines would give a greater picture of how fuel properties can help to influence PM emissions [10]. Unlike this previous work, the study reported here uses blends of M15.

The hydrocarbon composition of a fuel, especially aromatics, is known to influence PM emissions. On the other hand, oxygenates blended into a fuel have often been reported to suppress the development of particulate matter emissions. Vuk \& Vander Griend [11] reported in their research that high boiling point aromatics are the primary factor responsible for particulate emissions and are more prone to soot formation than paraffins or olefins. In another report by Karavalakis et al. [12], it was found that particulates in the accumulation mode were lowered by having more oxygenates content and a lower aromatic content in the fuel blend. The same trend was reported by Price et al. [13], that the presence of oxygenated compounds in combustion reduces the concentrations of key intermediate species that are required for the formation of the initial aromatic ring that is known to be a pre-cursor to soot particle inception. In a report by Sobotowski et al. [9] the aromatic contribution to particulate matter formation was less evident, however, for the case of lighter aromatics (such as toluene) whose boiling points fall well below the gasoline distillation end point.

\section{Flashing boiling atomization in a Spray Guided Direct Injection system}

Flash boiling and its disruptive break-up of the spray can be seen to enhance atomization, and therefore give a faster conversion of fuel droplets to fuel vapour [14]. These smaller droplets will also experience a greater deceleration due to drag, meaning that spray penetration is often reduced for a given fuel injection pressure [15]. Both of these factors are seen as potentiallybeneficial to avoiding excess particulate matter emissions, since localized rich mixture combustion (due to inhomogeneity) or liquid fuel combustion (due to unevaporated droplets and liquid films) are less likely.

However, at particularly high levels of superheat (very high saturation pressure ratio - the ratio of the vapour pressure to the system pressure), the penetration distance and rate of some multi-hole GDI injectors can start to increase, meaning piston crown wetting may become more likely [16]. The research by Zeng et al. [17] provides a very detailed investigation on the spray characteristics and structures using three single component fuels. The results were categorized into three regions of spray structure which are: flare flashing, transition and non-flash boiling regions. The findings show that changing the ambient to saturation pressure ratio could lead to significant changes in the spray structure. In particular, the vapour quantity reduction as the pressure ratio drops is expected as the liquid evaporates faster with a higher temperature, especially in the superheated region. Zeng et al. also report that spray penetration is reduced in the transitional regimes as the pressure ratio is increased, but after the tipping point at about a pressure ratio of 3.3, the flare flashing regime shows that penetration increases as the pressure ratio is reduced below 3.3. This contradicts some reports that say spray penetration will decrease if the fuel is superheated and flashes.

In addition, with a higher degree of superheat, much of the fuel's more volatile components may be converted to vapour early after the start of injection, leaving the droplets formed upon spray break-up depleted of volatile components and leading to a longer expected droplet lifetime. In conjunction with the charge cooling effect, the lifetime of early injected spray droplets may be increased to that expected from similar size droplets from a subcooled liquid spray. As explained in the M15 Fuels and Fuels Design section, there are differing reports in the literature regarding the impact of the methanol content on the PM emissions from GDI engines.

\section{EXPERIMENTAL PLANNING}

Two basic model fuels, Fuel A and Fuel B, containing $15 \%$ by volume methanol were used throughout all experiments, described in the 'M15 Fuels and Fuels Design' section. In order to understand better the sources of PM from GDI engines from these types of fuels, a series of studies was undertaken ranging from fuel spray imaging to particulate measurements from a single cylinder optical engine:

- Spray rig tests to isolate the effects of fuel volatility/fuel temperature on vaporization rate, flash boiling characterization, homogeneity characterization and penetration (by eliminating air motion).

- Motoring tests in an optical engine with a full optical liner in order to investigate interaction of the spray with the intake air motion and to 
assess the amount of impingement on the piston at different injection timings .

- Combustion imaging through a quartz optical annulus at around $20^{\circ}$ ATDC and onwards using a firing optical engine, with accompanying combustion burn rate analysis, in order to assess: the potential presence of diffusion flames resulting from piston impingement, the intensity of soot luminosity, and the effect of the spray character on the burn rate and combustion variability.

- Particulate measurement for both the metal engine build and the engine build with the quartz optical annulus. This gives PM information at various fuel temperatures for comparison with combustion and spray images and metrics, allowing analysis of the contribution to PM from some of the different available sources, i.e. piston/liner impingement, poor vaporization rate/available time for vaporization, poor homogeneity, surface temperatures (annulus/piston material), in-cylinder rich combustion.

The engine operating point was at $1000 \mathrm{rpm}$ with a light load of 0.5 bar manifold absolute pressure (MAP). This corresponds to a bmep of about 2 bar, since the engine uses Late Inlet Valve Closure. This condition is one where one would expect to find low cylinder pressures during early direct injection with the intake valves open and thus the possibility of highly superheated fuel sprays. The intake air was heated to $40^{\circ} \mathrm{C}$ to maintain consistency of the intake temperature as ambient air tem perature changes all the time.

\section{M15 Fuels and Fuels design}

The fuels tested in this work were selected in order to aid the understanding of mixture preparation in GDI engines, and the subsequent combustion and particulate emissions, when methanol-gasoline blended fuels are used. Gasoline blends containing a proportion of methanol have been studied previously in GDI engines and are found today in markets where methanol may be readily manufactured from non-petroleum sources to supplement the traditional supply of gasoline for spark ignition engine use [18-20]. Here, a proportion of $15 \%$ by volume was chosen as representative of a commonly used low methanol content gasoline [18], which is known as 'M15'.

Methanol provides several potentially useful changes to physical properties when it is blended with gasoline such as: lowering the initial boiling point (making the fuel more susceptible to flash boiling); increasing the fuel volatility to enhance fuel spray evaporation rate; increasing the overall octane number; providing oxygenate content to the fuel, (which may be beneficial towards reducing particulate emissions at various engine conditions [13]); increasing the fuel latent heat, (which can increase charge cooling and increase volumetric efficiency). Literature reports of the emissions of
M15 or similar methanol-gasoline blends running in GDI engines tend to report a decrease in measured particulate mass across a drive cycle, whereas the reports on whether M15 causes an increase or decrease in particulate number emissions are mixed [19-21].

The lowering of the initial boiling point, due both to methanol's high volatilityas a pure component, and also the highly non-ideal behaviour of mixtures of hydrocarbons with methanol, means that dis ruptive flash boiling atomization is observed at lower saturation pressure ratios than for similar fuels containing ethanol or no oxygenates at all. The saturation pressure ratio is defined here as the ratio of the fuel's vapour pressure $p_{\text {vap }}$ (at its temperature leaving the injector) to the cylinder pressure $\mathrm{p}_{\text {cyl }}$.

Two fuels ( $A$ and $B$ ) have been used here that have a similar vapour pressure (calculated at $311 \mathrm{~K}$ ) and similar early distillation curves up to the T50 point. However, Fuel B contains around $28 \%$ aromatic components (in the form of toluene) and a characteristic heavy end to the distillation curve with a T90 of $420 \mathrm{~K}$. This represents a fuel whose hydrocarbons replicate the volatility and fraction evaporated specifications for a typical gasoline [22] with a very high vapour pressure due to the addition of $15 \%$ by volume methanol. Previous experience with similar fuels has shown a high level of particulate emissions results with $\mathrm{M} 15$ fuel. In addition, two variants of Fuel $A$ have been used Fuel $A^{+}$is more volatile as it contains $80 \% n$ pentane, and Fuel $A^{-}$that is less volatile as it contains no n-pentane.

The non-ideal fuel effects were accounted for by using the UNIFAC method, as implemented by Camm etal. [23], and the component fractions were varied to achieve the desired aims. The compositions of Fuel $A$ and Fuel $B$ are shown in Table 1. Fuel $A$ has $3 \%$ by volume Iso-butanol added to act as a co-solvent between the methanol and hydrocarbon components in order to prevent phase separation. 
Table 1. Composition of the test fuels; Fuel $B$ has a heavy end and contains toluene, while Fuels $A^{-}, A$ and $A^{+}$(in order of increasing volatility) only contain alkanes and alcohols.

\begin{tabular}{|c|c|c|c|c|c|c|c|}
\hline 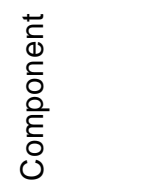 & 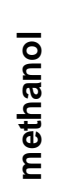 & 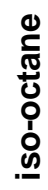 & 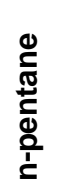 & 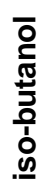 & $\begin{array}{l}\stackrel{\Phi}{\frac{C}{0}} \\
\stackrel{0}{2}\end{array}$ & 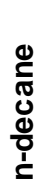 & 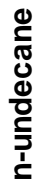 \\
\hline $\begin{array}{l}\text { \% by } \\
\text { volume in } \\
\text { Fuel } A\end{array}$ & 15 & 42 & 40 & 3 & 0 & 0 & 0 \\
\hline $\begin{array}{l}\text { \% by } \\
\text { volume in } \\
\text { Fuel } A^{-}\end{array}$ & 15 & 82 & 0 & 3 & 0 & 0 & 0 \\
\hline $\begin{array}{l}\text { \% by } \\
\text { volume in } \\
\text { Fuel } A^{+}\end{array}$ & 15 & 2 & 80 & 3 & 0 & 0 & 0 \\
\hline $\begin{array}{l}\text { \% by } \\
\text { volume in } \\
\text { Fuel B }\end{array}$ & 15 & 0 & 45 & 0 & 28 & 7 & 5 \\
\hline
\end{tabular}

The modelled distillation curves are presented in Figure 1. The saturation pressure ratio for each experiment in the spray rig (ambient pressure = $1.013 \mathrm{bar}$ ) and in the engine (cylinder pressure = 0.5 bar) at each of the temperatures studied is shown in Table 2

Table 2. Fuel saturation pressure ratios for Fuels $A$ and $B$ only. The matched highlighted entries show similar ratios that may be used for comparison betw een spray rig images and engine studies

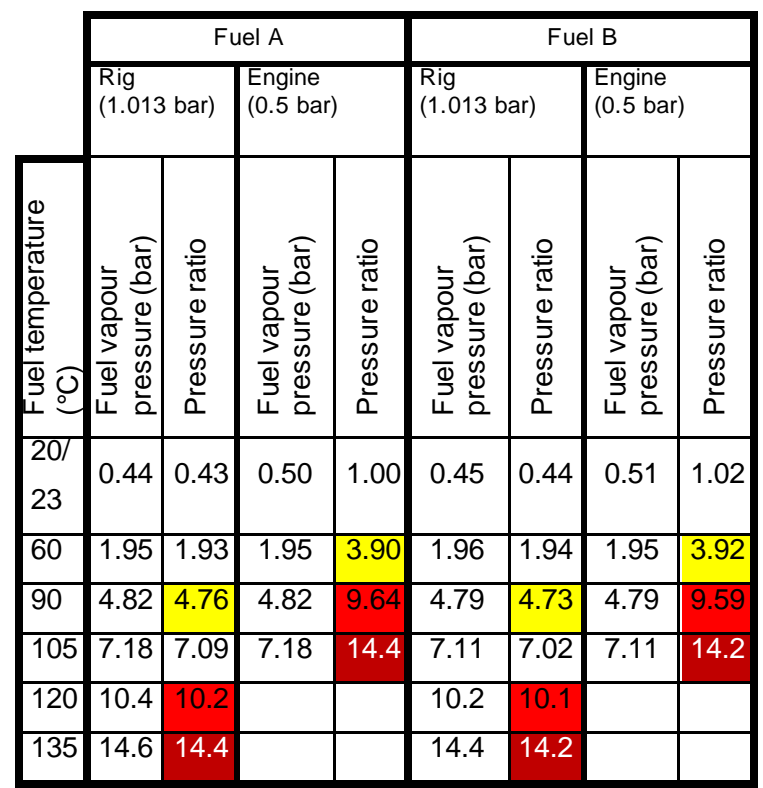

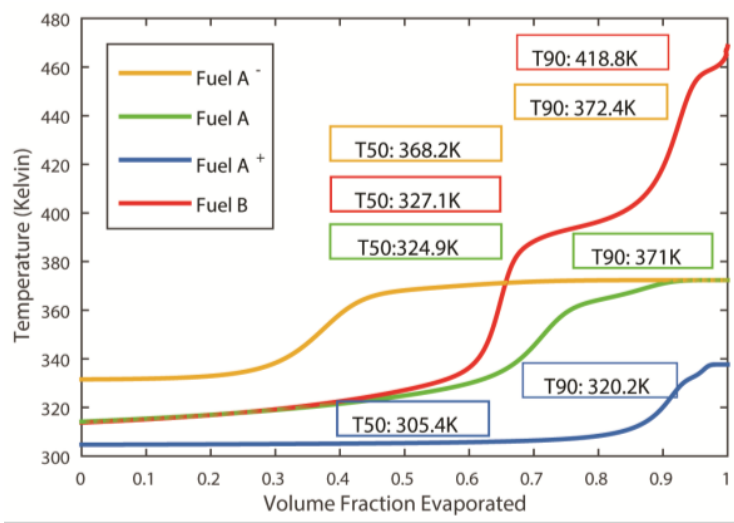

Figure 1. Distillation curves for the test fuels. The modelled distillation curves track a temperature trajectory required to give fuel vapour pressure of $1.013 \mathrm{bar}$ and therefore do not directly reflect the ASTM D86 procedure in the early stages of distillation as no account is taken of dissolved gases and no liquid is evaporated until the vapour pressure reaches 1.013 bar.

The fuels were designed by looking at their saturation pressure ratio for various fuel temperatures. In the spray rig experiments, the fuel temperature was set equal to the fuel injector block temperature, which was soaked for a period of 30 minutes at each test temperature before the fuel injection was begun. In the optical engine studies, the fuel temperature was assumed to be equal to the coolant temperature, which was constantly circulating through the cylinder head during the test. In each case, there are factors which may cause the liquid fuel temperature during injection to differ from the temperature of the injector and metal block or cylinder head. In both cases, cold fuel will be constantly drawn from the unheated fuel line into the hot injector and will take time to heat up to its temperature set point. However, the small clearances and rapid motion of the fuel in the injector sac and nozzle can cause high shearing and heating of the fuel before it leaves the injector. In the spray chamber the injector tip is adjacent to colder air inside the chamber, whereas in the engine the injector tip is adjacent to the cycle of hot and cold gases in the combustion chamber. 


\section{EQUIPMENT}

\section{Spray Rig}

The injector is a multi-hole six nozzle spray guided injector for direct injection provided by Jaguar Land Rover. High speed images of fuel sprays were captured using a continuous flow atmospheric pressure spray chamber and a Photron Fastcam $1024 \mathrm{PCl}$ camera. The spray chamber is open to the atmosphere at the top and air is drawn out of the bottom by an extraction system, which purges the fuel vapour and remaining spray droplets out of the visible portion of the chamber between sprays. The injector can therefore be operated continuously; in these tests $5 \mathrm{~Hz}$ was chosen. The chamber uses a full optical cylinder liner from the Jaguar optical engine that was used in this work, and the injector is centrally mounted as in the engine. Therefore, analysis of wall wetting, plume penetration and how spray droplets fill the cylinder will be directly relevant to the conditions in the engine. The vertically-oriented spray chamber is shown in Figure 2.

The fuel is pressurized using a static piston pump using compressed air at $\sim 2.5 \mathrm{bar}$. This acts on one side of a metal piston, which through an area ratio of around 60 gives a fuel pressure of 150 bar on the other side of the piston. Pulses are sent to a Bosch injector driver from a bespoke LabVIEW system with fully configurable injection duration and injection period. The multi-hole injector is fitted into the top of the spray chamber in a heated injector block. The temperature of the block is also controlled via the LabVIEW system using temperature feedback control. Temperature is measured using a platinum resistance thermometer set into the block located $20 \mathrm{~mm}$ from the injector tip. At each temperature set point, there was a 30 minute soak period so that the temperature of the fuel in the injector was taken to be the same as that of the thermometer.

The purge rate of the cylinder was set so that all air and fuel vapour would leave the chamber in the 200 $\mathrm{ms}$ between injections. The mean downwards axial flow velocity was set to be below the recommended limits for GDI sprays [24] so as not to disturb the spray.

The images were taken at 4500 frames per second with the camera (CMOS) at a distance of around $830 \mathrm{~mm}$, using an $\mathrm{f} / 1.2$ lens. The exposure was set to $3.30 \mu$ s to capture as much transient detail of the spray as possible. The sprays are illuminated from the side using a $100 \mathrm{~W}$ LED array, which is pulsed and overdriven to $50 \mathrm{~V}$ and $20 \mathrm{~A}$. Light from this is focussed towards the spray using a spherical lens to allow more light to be incident onto the spray. The inside of the cylinder, behind the spray, is covered in black card to give a black background for the spray. In this work, each spray was imaged for 50 frames, which is up to $11 \mathrm{~ms}$ after SOI, and 50 shots were performed at each temperature.

\section{Optical Engine}

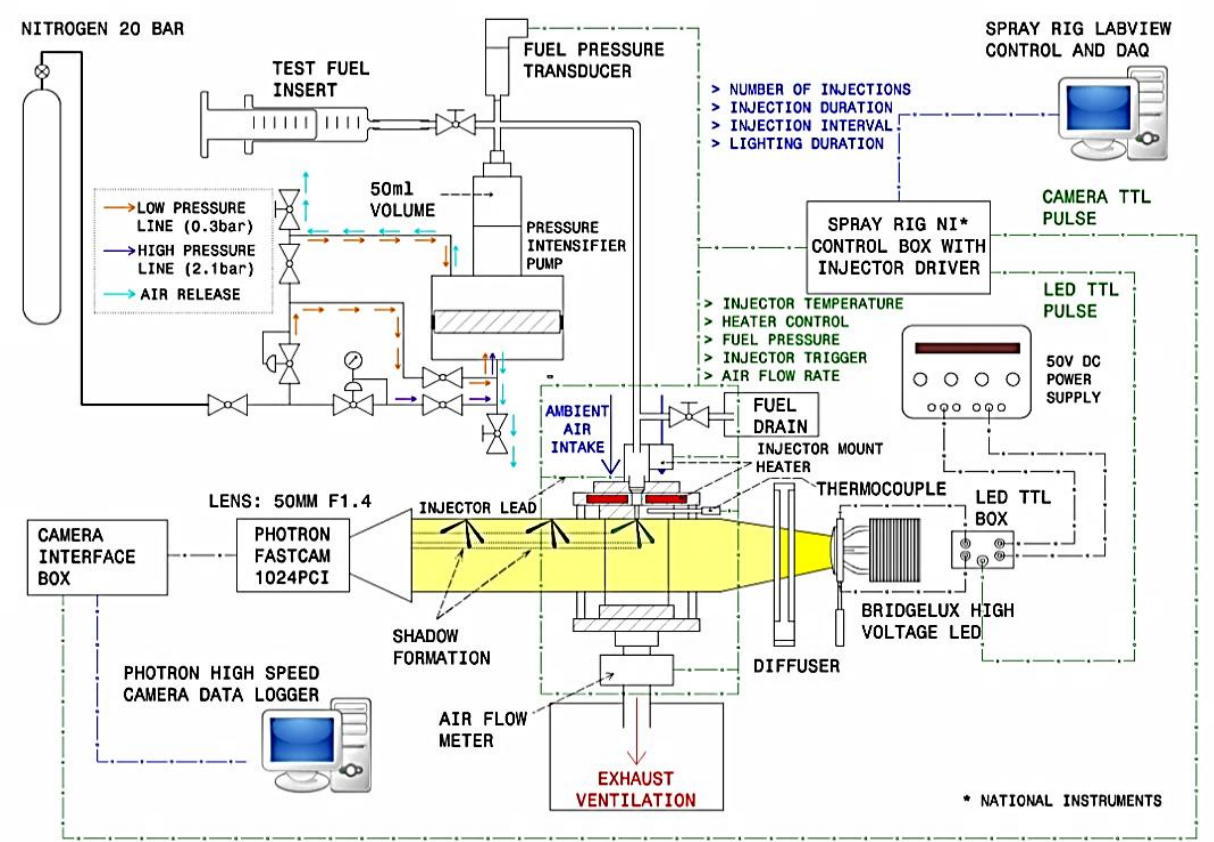

Figure 2. Schematic of the spray rig experimental setup.

Page 5 of 18 


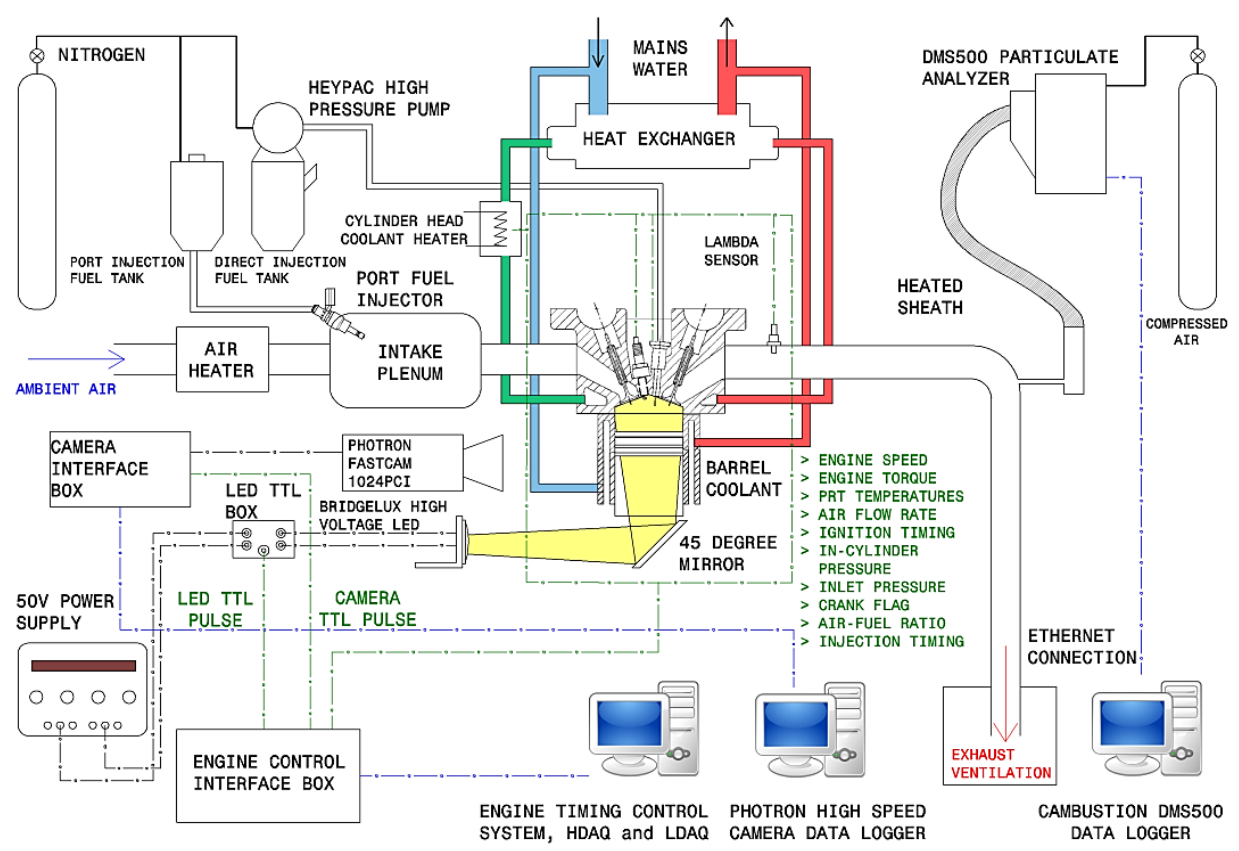

Figure 3. Schematic of the optical engine experimental setup.

The optical engine used for this research has a cylinder head structure which is the basis of the Jaguar AJ133 combustion system, and it has a modular cylinder barrel build where many types of optically accessed components can be assembled. One of the prominent features of this optical engine is the Bowditch piston assembly which houses a static 45 degree mirror for optical access from underneath the piston as shown in Figure 3 . Usually, images are taken through the mirror but for this research, the high power LED is used with the mirror to illuminate the spray in the combustion chamber. The full specification of the optical engine is shown in Table 3.

Table 3. Single cylinder optical engine specification

\begin{tabular}{|l|l|}
\hline Bore (mm) & 89 \\
\hline Stroke (mm) & 90.3 \\
\hline Cylinder capacity (cc) & 562 \\
\hline Compression ratio & 11.1 \\
\hline $\begin{array}{l}\text { Direct injection fuel pressure } \\
\text { (bar) }\end{array}$ & 150 \\
\hline Port fuel injection pressure (bar) & 3 \\
\hline IVO (CAD ATDC) & 33.5 \\
\hline IVC (CAD ATDC) & 241.5 \\
\hline EVO (CAD BTDC) & 245 \\
\hline EVC (CAD BTDC) & 5 \\
\hline
\end{tabular}

The holes in the injector were designed for the AJ133 engine to meet a specific targeted spray foot print.

Page 6 of 18
Particulate number and size spectra were measured using a Cambustion DMS500 Mark II Fast Particulate Spectrometer.

\section{SPRAY RIG RESULTS AND ANALYSIS}

Using the spray rig, both sprays from Fuel A with $40 \%$ by volume $n$-pentane and sprays from Fuel B were imaged using side illumination (Mie Scattering) and back illumination through a diffusive screen. Tests were performed at the fuel temperatures of $20^{\circ} \mathrm{C}, 60^{\circ} \mathrm{C}, 90^{\circ} \mathrm{C}, 105^{\circ} \mathrm{C}, 120^{\circ} \mathrm{C}$ and $135^{\circ} \mathrm{C}$ giving the fuel pressure ratios shown in Table 2.

\section{Mie Scattering images}

A set of 50 spray images for each fuel and at each temperature was subject to background subtraction then thresholding to identify the spray plumes. Two thresholding strategies were tested: a flat threshold of $8 \%$ and a varying threshold that started at $8 \%$ and reduced to $2 \%$ by the $50^{\text {th }}$ image. By inspection, the $8 \%$ threshold gave a good qualitative representation of the early spray but missed much of the spray after EOI, which was captured best with a $2 \%$ threshold. However, with the $2 \%$ threshold spurious light is captured earlier on.

After thresholding, the axial penetration was calculated (not accounting for perspective errors) and spray pixel values summed to give a spray integral indicative of the amount of spray present. In Figure 4 , the spray axial penetration for Fuel $B$ is presented for both thresholding methods. The error bars show one standard deviation from 50 images for the varying threshold and show there is a good comparison in spray penetration between the two 
methods. The varying threshold technique was used to give more detail about the later part of the spray after EOI.

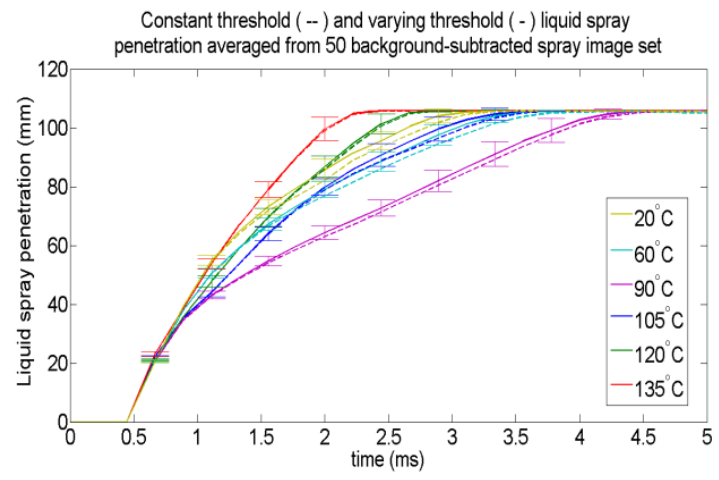

Figure 4. Spray penetration comparison from the two thresholding techniques. Each spray reaches a steady value once it leaves the field of view. The varying threshold reduced from $8 \%$ at SOI to $5 \%$ at EOI and $3 \%$ at $4 \mathrm{~ms}$ ASOI.

In addition, a set of pixels where some light incident on the outside of the barrel is reflected towards the camera to give an intense (but unsaturated) patch of light was used in order to monitor the illumination level throughout the imaged period. An example image is shown in Figure 5. The sum of pixel values from this area was recorded and showed a decreasing level of light as the injection proceeded. This is concomitant with the measured reduction of current through the LED after initial energizing. The value of the spray pixel integral recorded for each image was weighted by this estimate of incident light.

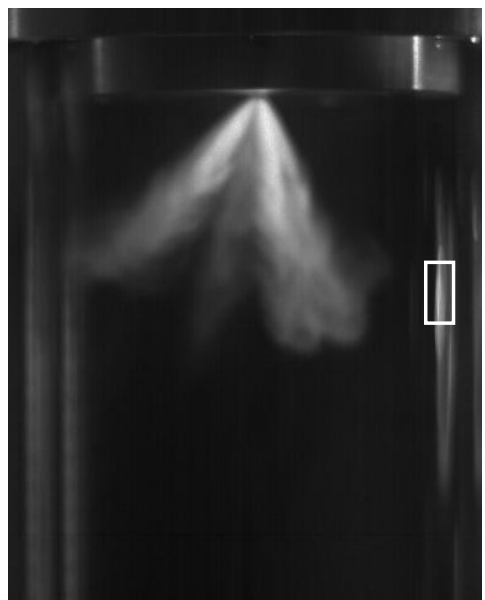

Figure 5. Typical illuminated spray image and location of $w$ indow that $w$ as monitored to estimate the light actually incident on the spray during any given frame.

The light level weighted spray pixel integrals for Fuel $A$ and Fuel $B$ are shown in Figure 6, for the full range of fuel temperatures using the varying threshold. Vertical dotted lines of appropriate colour indicate the mean time at which the tip of a spray begins to leave the field of view. The observed

Page 7 of 18 trends were replicated in the constant threshold investigation.

The heavier Fuel B shows a larger absolute value of peak spray integral, across all temperatures apart from the cold room temperature condition. This trend is also seen in the unweighted spray integral results, which are not shown here. Both fuels have similar initial boiling points and vapour pressures but Fuel B has a much higher T90 and final boiling point, so droplet lifetime would be expected to be longer. This difference in expected droplet vaporization lifetimes is manifest in terms of the amount of liquid present (in terms of both number and size of droplets) even before $\mathrm{EOI}$, for the sprays at $60^{\circ} \mathrm{C}$ and above. However, differences in how these fuels flash boil may be contributing factors to the differences in light levels. Fuel A may produce a more sparsely packed spray or smaller droplets due to differences in the character of flash boiling atomization that each spray undergoes, in turn due to the different evaporative performance seen in the distillation curve, Figure 1. When the sprays collapse to a greater extent, due to a higher superheat degree, more liquid fuel will be obscured behind the visible part of the spray, which could affect the trends here.
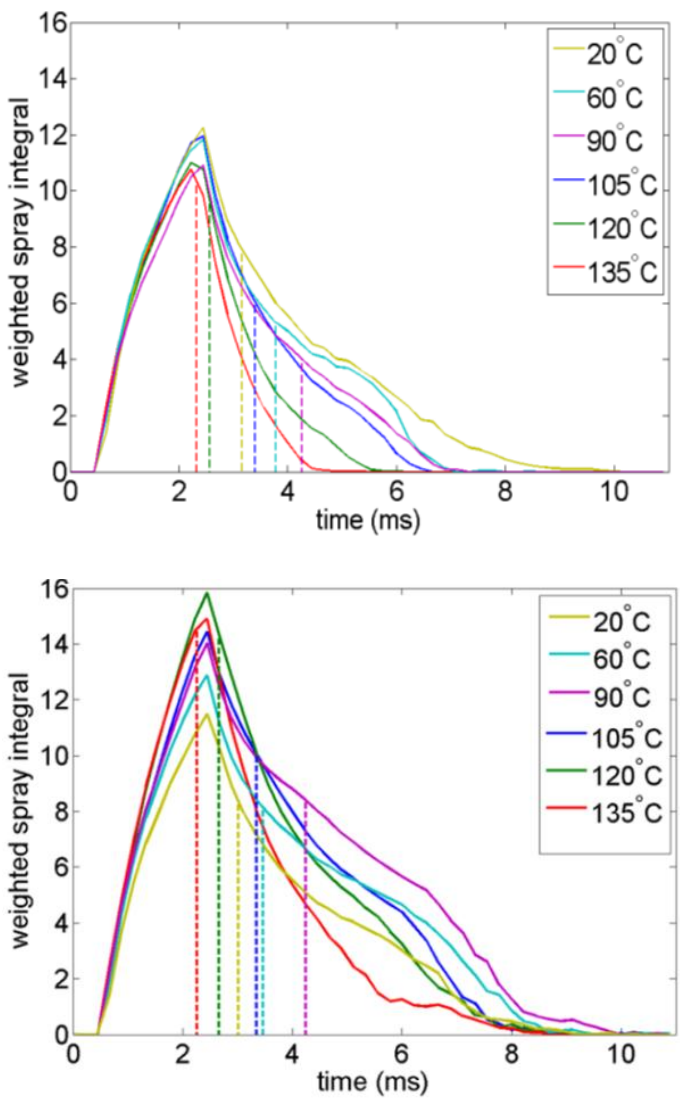

Figure 6. Spray pixel integrals for Fuel A (top) and Fuel B (bottom) averaged across 50 sprays, the broken line indicates $w$ hen the tip of the fuel spray leaves the field of view .

The degree to which the spray droplets spread out within the cylinder can be examined by looking at 
the axial penetration of both the spray tip and the trailing edge of the spray as it leaves the injector. Both the maximum and minimum mean penetrations are plotted in Figure 7, for each fuel temperature measured. Each curve ends at the time when the mean spray integral for that spray went to zero, when all the droplet have evaporated or moved out of the measurement area.

The spray tip penetration rate decreases as the fuel temperature rises before beginning to increase again after a minimum at $90^{\circ} \mathrm{C}$ for both fuels, as predicted by previous literature studies [16] [17]. The fuel saturation pressure ratio at $60^{\circ} \mathrm{C}$ was around 2 and at $90^{\circ} \mathrm{C}$ it was around 5; and this is consistent with the minimum penetration pressure ratio predicted in [19] of 3.33. This is hypothesized to begin when the multi-hole plumes begin to coalesce into one downwards travelling jet, thereby concentrating each plume's momentum in a common direction and counteracting the effects of reduced droplet size. However, it must be noted that the air that the fuel was injected into was heated indirectly by contact with the heated injector block; the air temperature increased to $40^{\circ} \mathrm{C}$ at the highest fuel temperature. This produces two additional competing effects: reduced chamber air density with reduced droplet drag and increased droplet evaporation rate causing reduced droplet size and higher droplet drag.
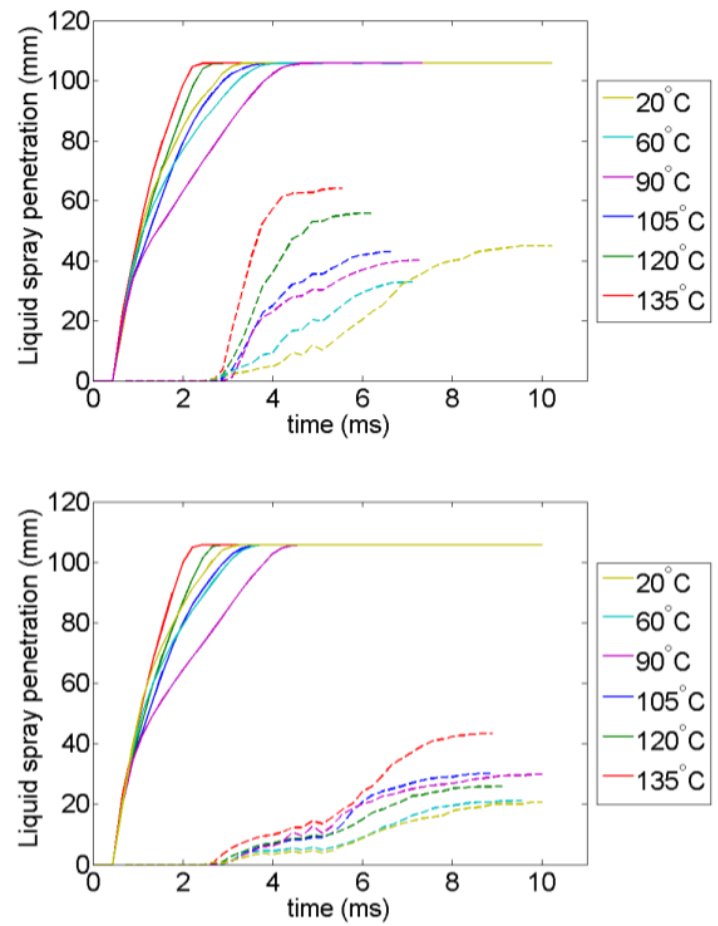

Figure 7. Leading (-) and trailing (--) edge spray penetrations from the Mie Scattering images for Fuels A (top) and Fuel B (bottom).
There was a general trend that increasing the temperature increased the penetration rate of the spray trailing edge. As all of the spray plumes begin to be turned towards the axial direction during spray collapse, this is to be expected. This phenomenon may influence the amount of liquid that is deposited onto the piston crown or the amount of vapour that is initially deposited in different parts of the combustion chamber. These trailing edge spray droplets moved less quickly in the Fuel B experiments, probably due to their larger size with this fuel.

Figure 8 is a selection of individual images from the experiments with Fuels $A$ and $B$, with false colouring of the identified spray region. These show the distribution of the spray around the cylinder for both fuels across the range of temperatures.

The hottest spray at $135^{\circ} \mathrm{C}$ shows the most intense region nearest the injector tip due to collapse of the plumes into each other. This creates a dense region of droplets here, which, in terms of light scattering, seems to dominate over any reduction in droplet size. In addition, the structure of the spray at this temperature is more jet-like with a narrower overall spray angle, which avoids liner impingement but leaves areas near the top of the cylinder to the sides of the injector without any droplets, as seen in previous work for sprays at the highest superheat levels [16] [17]. Between the fuels, there is little difference until after EOI, suggesting it is the early part of the fuel distillation curve that dominates the spray structure during injection, even at high levels of superheat.

\section{Backlit images}

Backlit images were used to identify the spray angles in accordance with SAEJ2715 [24] for the Fuel $A$ variants at a range of fuel temperatures, to quantify the amount of spray collapse induced by flash boiling. Figure 9 shows a plot of the spray angle at four different temperatures. All of the images shown were taken at $1.5 \mathrm{~ms}$ after the first appearance of the fuel. As predicted, the most volatile fuel $\mathrm{A}^{+}$collapsed tremendously and developed the narrowest spray angle at the highest temperature. This is a reduction of approximately $33 \%$ of the spray angle for this fuel when the tem perature changes from $23^{\circ} \mathrm{C}$ to $105^{\circ} \mathrm{C}$ whilst the least volatile fuel only changed by $20 \%$. This confirms the trend, observed here and noted in the literature [16] [17] for multi-hole injectors, that increasing levels of superheat would cause a greater collapse of the spray, grouping the plumes together and causing the fuel to be concentrated into a narrower region. 


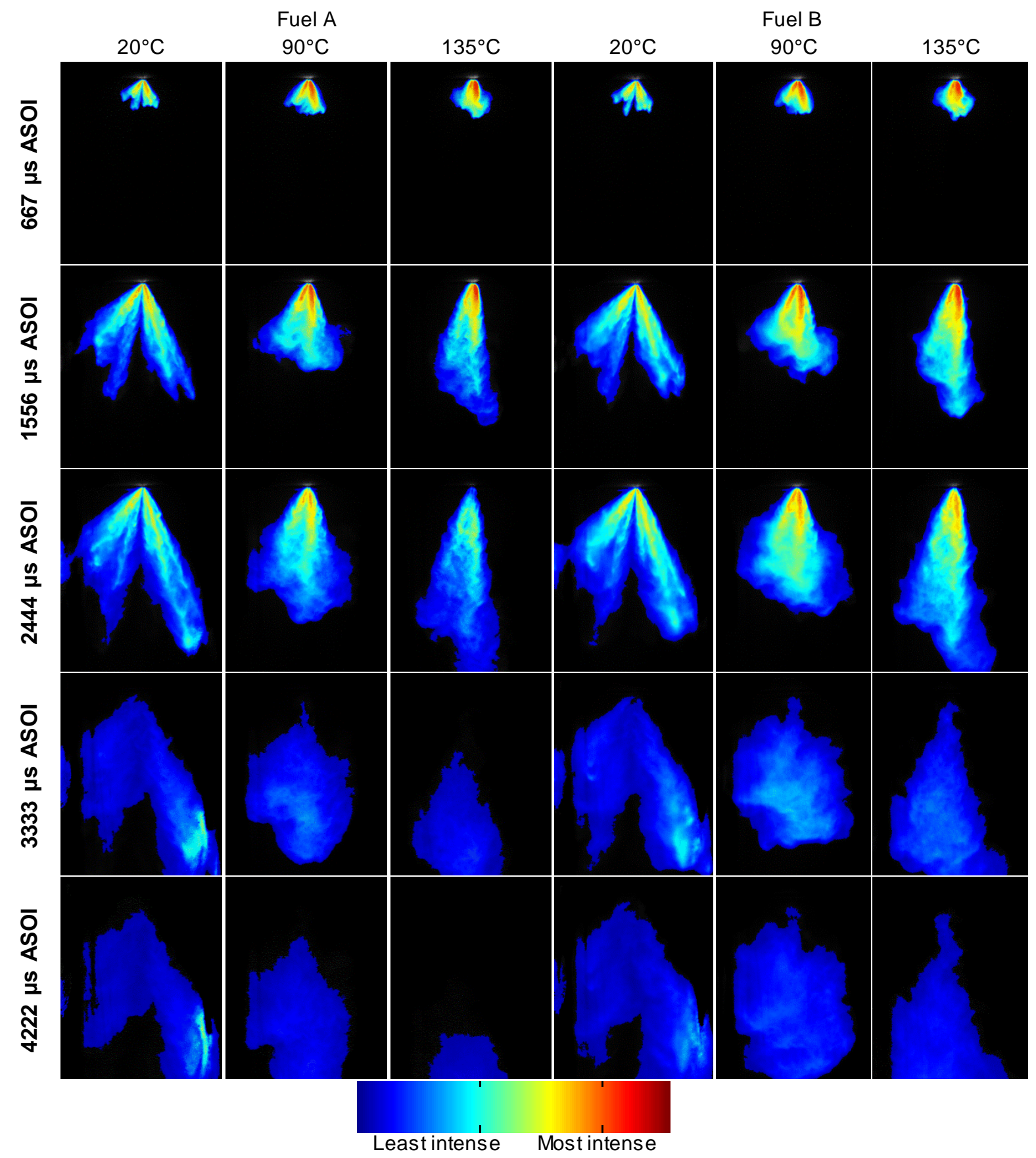

Figure 8. Sample individual spray images for three temperatures and for fuels $A$ and $B$, show ing the variations in how each fuel and fuel temperature combination fills the cylinder w ith spray (each image displays time as $\mu s$ ASOI). The demanded injection duration was $2 \mathrm{~ms}$. 


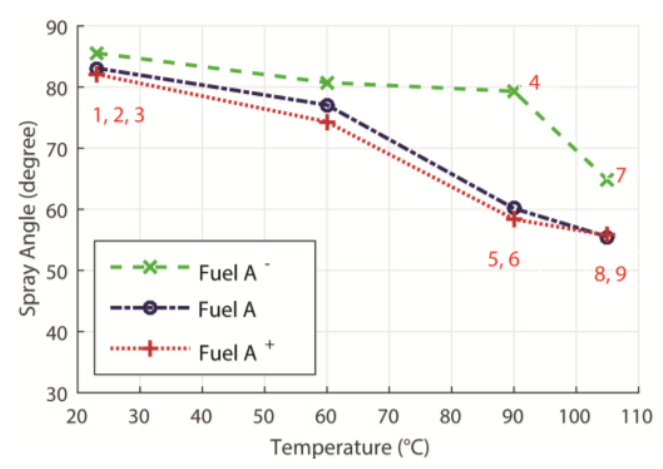

Fuel $A^{-}$

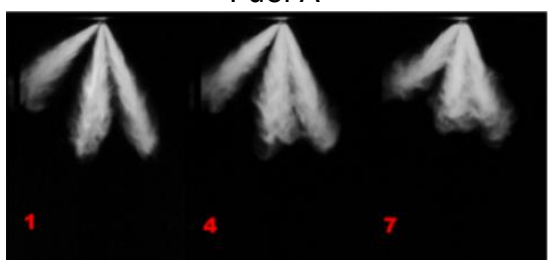

Fuel A

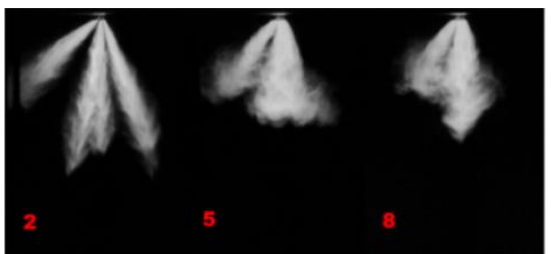

Fuel $\mathrm{A}^{+}$

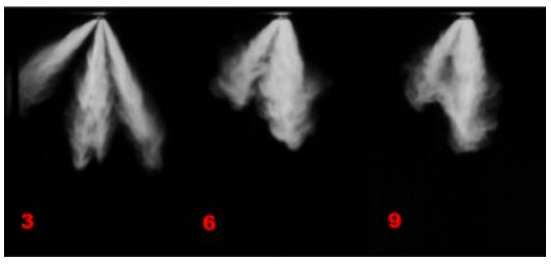

Figure 9. Variation of overall spray angle $w$ ith temperature for Fuels $A^{-}, A$ and $A^{+}$and sample images $(1.5 \mathrm{~ms}$ after the appearance of the fuel) to illustrate various degrees of spray collapse. Taken from spray imaging experiments w ith back illumination.

\section{MOTORING SPRAY IMAGING RESULTS}

Spray imaging in optical engine can portray valuable characteristics of the spray when being injected into the cylinder. In contrast to the spray rig, the cylinder pressure in the engine is below atmospheric pressure, and can vary during early injection. This in turn changes the condition of the fuel when injected into the cylinder. The motoring experiments were conducted with all of the four fuels mentioned in the M15 Fuels and Fuels Design section. Figure 10 shows the measured trace of the optical engine cylinder pressure during the intake stroke for the engine with a coolant temperature of $23^{\circ} \mathrm{C}$. As shown in the figure 10 , the intake pressure dropped from almost atmospheric as the exhaust valves are closed to as low as 0.39 bar at $310^{\circ} \mathrm{BTDC}$ before returning to the nominal value of 0.5 bar from $280^{\circ} \mathrm{BTDC}$ onwards.

It can also be seen that cylinder pressure increases slightlyas the fuel is injected. The spray tip velocity is difficult to trace in the optical engine without access to the pent-roof window, therefore a simpler average tip velocity is calculated from observation of the fuel impingement onto the piston surface using the high speed camera and the calculated piston displacement distance from the injector tip.

Figure 11 shows how the cylinder pressure at start of injection varies with the increase of engine coolant temperature from $23^{\circ} \mathrm{C}$ to $105^{\circ} \mathrm{C}$. The cylinder pressure, when at $250^{\circ} \mathrm{BTDC}$ and $280^{\circ}$ BTDC, both show a $10 \%$ increase of pressure from the lowest to the highest temperature. As for injection at $310^{\circ} \mathrm{BTDC}$, the plot shows a drop with a similar magnitude of $10 \%$ when the engine coolant is at $105^{\circ} \mathrm{C}$, which is an inverse trend to the later timings.

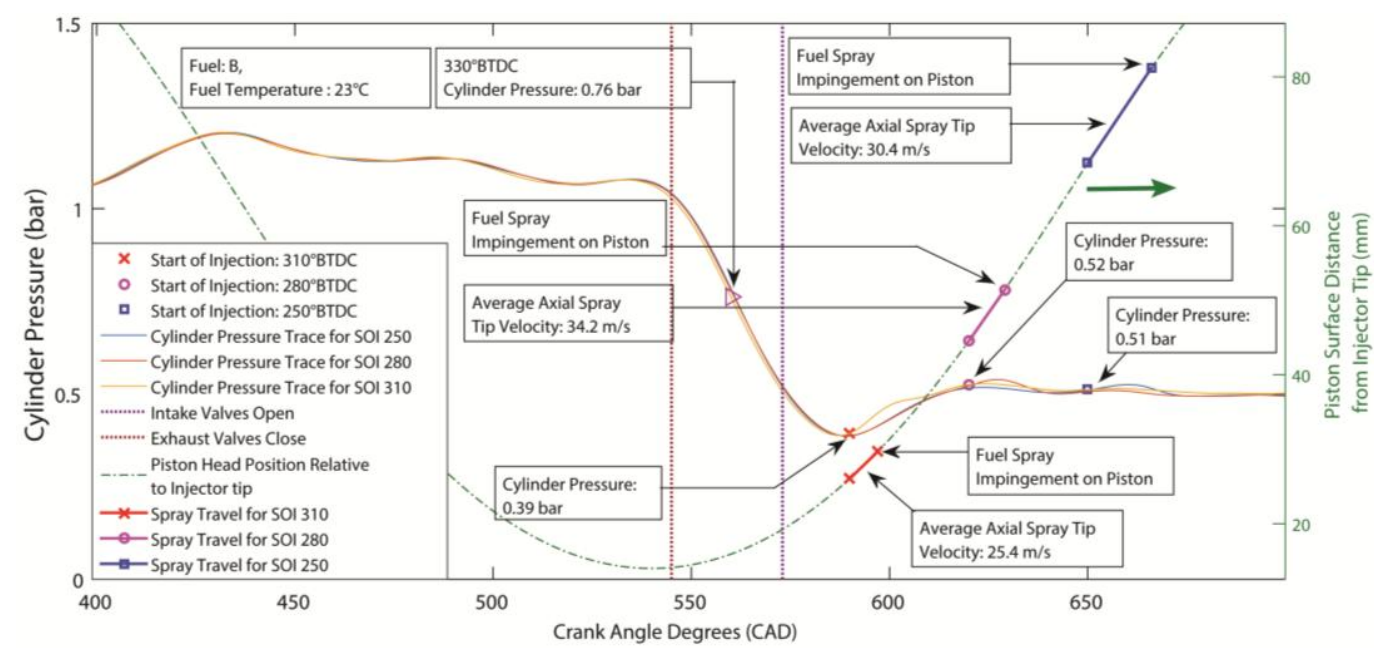

Figure 10. Optical engine motoring condition during the intake stroke at an engine coolant temperature of $23^{\circ} \mathrm{C}$. 
The ambient condition for the $310^{\circ} \mathrm{BTDC}$ at $105^{\circ} \mathrm{C}$ temperature dropped to a cylinder pressure of 0.36 bar which can definitely cause an extreme flash boiling phenomenon for the fuel as the pressure ratio $\left(\mathrm{p}_{\mathrm{vap}} / \mathrm{p}_{\mathrm{cyl}}\right)$ is already at 13.11 . This change in fuel atomization will almost certainly result in different particulate matter emissions. This suggests that the cylinder pressure change due to engine coolant temperature can change the flash boiling condition.

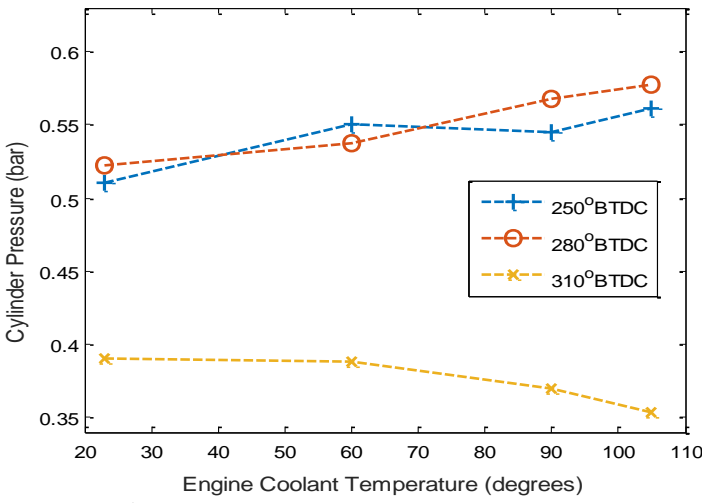

Figure 11. Cylinder pressure change $w$ ith engine coolant temperature.

Figures 12 and 13 show the semi-quantitative measurements of spray intensity for Fuels $B$ and the heavier Fuel $A\left(A^{-}\right)$at different temperatures and injection timings. In a Mie-scattering setup, fuel droplets that remain in liquid form will continue to scatter light till they change into vapour. Evaporation performance is measured by the amount of time the fuel spray remains in liquid form.

The spray images taken using the high speed camera were processed using MATLAB by summing the pixel intensity of a background subtracted image at every CAD. A standard deviation value was then calculated from the 10 cycles of spray imaging and used for plotting error bars. All of the A fuels show the same trends for all injection timings, with Fuel $A^{-}$evaporating slowest at both low and high temperatures while Fuel $A^{+}$ evaporates fastest when injected at the highest temperature of $105^{\circ} \mathrm{C}$. The magnitude of the pixel intensity for all fuels at the injection timing $310^{\circ}$ BTDC was lowest due to impingement of fuel on the piston surface as well as the higher flash boiling condition because of the lower in-cylinder pressure.

Fuel $B$ was tested under similar conditions to the experiments with Fuel $A$. It has to be noted that the magnitude of the spray intensity between fuels cannot be compared. This is because the tests were conducted on a different day, between which the imaging equipment was removed and reinstalled. This may cause variations in the illumination setup or engine condition (such as cleanliness of the quartz barrel that can let through more light to the camera). These results were analysed to investigate the evaporative performance and pattern of Fuel B that has a high T90 temperature. It can be seen in Figure 12 that at all injection timings the fuel evaporation was very poor with a fuel temperature of $23^{\circ} \mathrm{C}$ but improved to achieve a similar evaporation rate to that of the Fuel $\mathrm{A}$ when at temperatures of $90^{\circ} \mathrm{C}$ and $105^{\circ} \mathrm{C}$. At high temperatures, the fuel spray has a higher tip velocity and impinges on the piston leaving only some of the total fuel to disperse in the cylinder before evaporating. The persistence of the fuel suggests that it remains present in liquid form but probably in smaller droplet sizes.
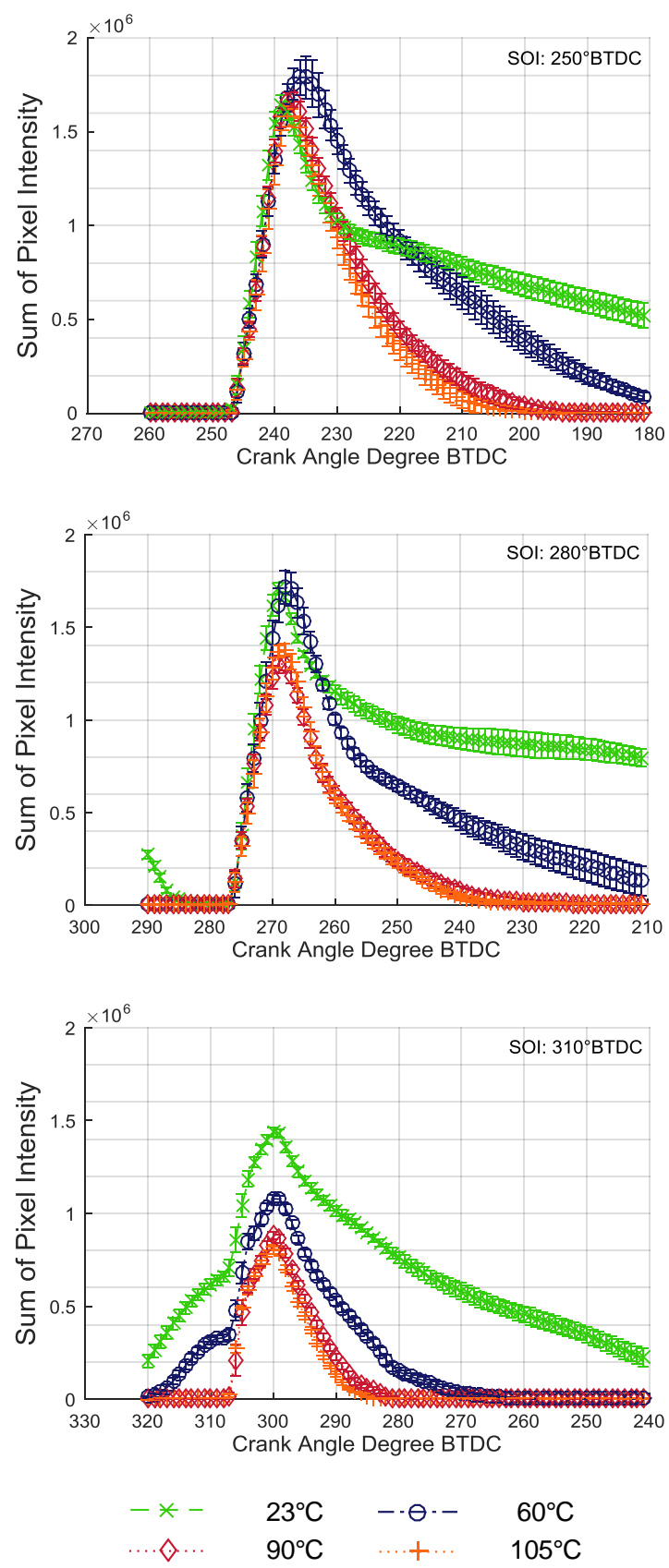

Figure 12. Integration of the of pixel intensity for Fuel B spray during engine motoring at injection timings of $310^{\circ}$, $280^{\circ}$ and $250^{\circ}$ BTDC to give a semi-quantitative measurement of the fuel quantity present. The error bars show the standard deviation from 10 measurements. 

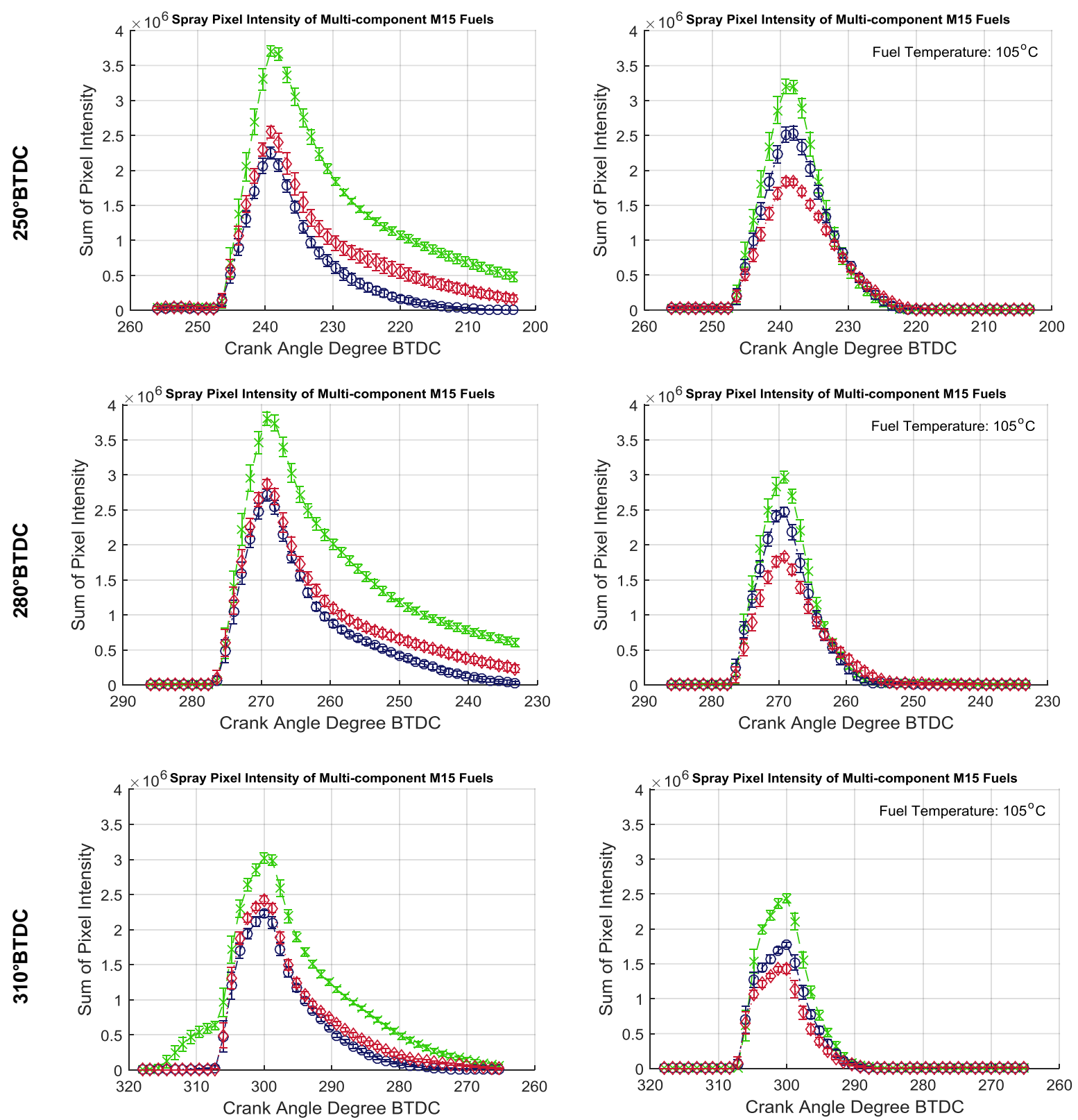

$$
-*-\text { Fuel } \mathrm{A}^{-}
$$

$-\cdot \theta \cdot-$ Fuel A

$\therefore$. $\gg$ Fuel $A^{+}$

Figure 13. Integrated pixel intensity for fuels $A^{-}, A$ and $A^{+}$sprays during engine motoring at injection timings of $250^{\circ}, 280^{\circ}$ and $310^{\circ} \mathrm{BTDC}$ at temperatures of $23^{\circ} \mathrm{C}$ and $105^{\circ} \mathrm{C}$ to give a semi-quantitative measurement of the fuel quantity present. The error bars show the standard deviation from 10 measurements.

Figures 14 and 15 show a spray distribution analysis of the 'heavy' fuel during motoring in the optical engine for injection timings of $250^{\circ}$ and $280^{\circ}$ BTDC respectively. Spray tip penetration alone does not necessarily portray the severity of the fuel impingement on the piston. To quantify these effects, the pixel intensity along a row was measured at 5 pixel rows above the piston and this was used to assess the severity of the piston wetting. The pixel intensity measured along a row was at 50 pixel rows above the piston to show the width of the spray and indicate if the spray had collapsed.
For both injection timings, it can be seen that the spray was still divided into two sections at temperature of $23^{\circ} \mathrm{C}$ suggesting that the original spray plumes still exist. For the case of $60^{\circ} \mathrm{C}$ fuel temperature, the spray spreads wider and covers a greater volume of the combustion chamber. At $90^{\circ} \mathrm{C}$ and subsequently $105^{\circ} \mathrm{C}$ the spray begins to collapse and creates a narrower geometry moving towards the piston. The spray intensity at $105^{\circ} \mathrm{C}$ produced the highest value of pixel intensity suggesting a higher droplet density (smaller droplet spacing-to-diameter ratio) and therefore higher local droplet surface area with this spray, possibly due to 
the concentration of droplet as the plumes are drawn together.

$60^{\circ} \mathrm{C}$

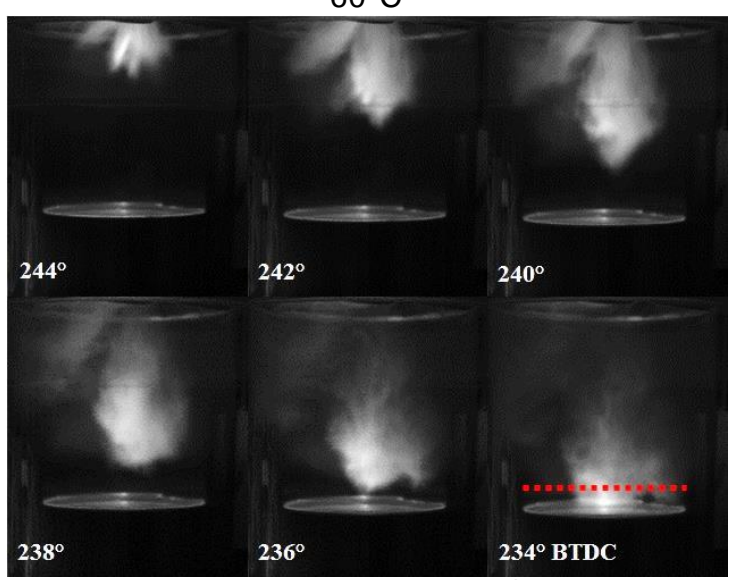

Dimensions: 384 x 448 pixels per image. Scale: $0.25 \mathrm{~mm}$ per pixel
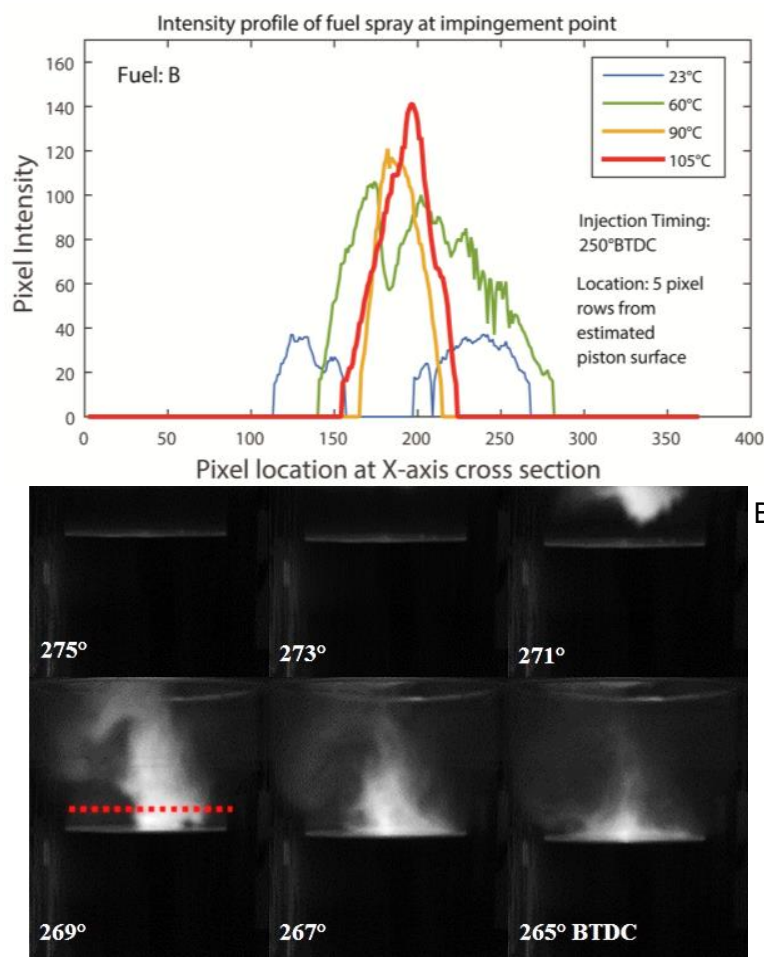

Dimensions: 384 x 448 pixels per image. Scale: $0.25 \mathrm{~mm}$ per pixel

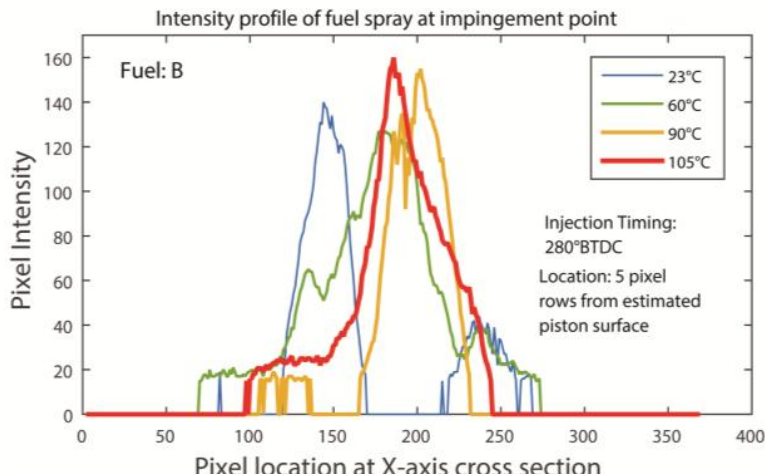

$105^{\circ} \mathrm{C}$

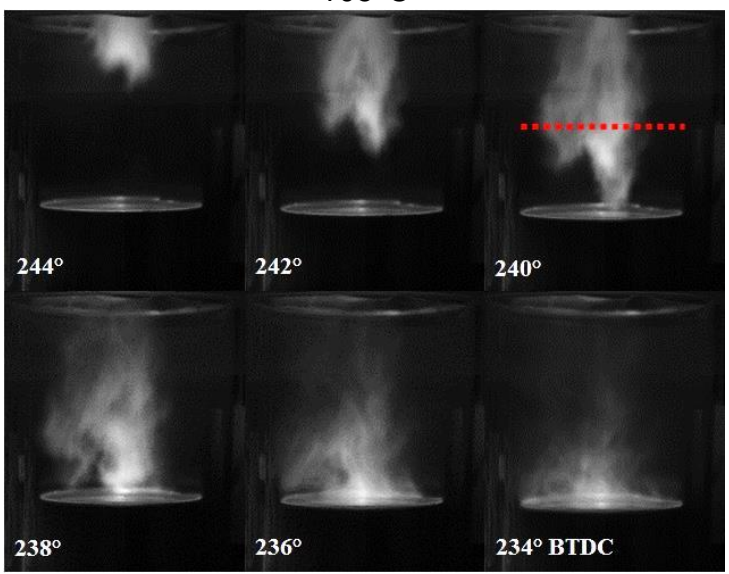

Dimensions: 384 x 448 pixels per image. Scale: $0.25 \mathrm{~mm}$ per pixel
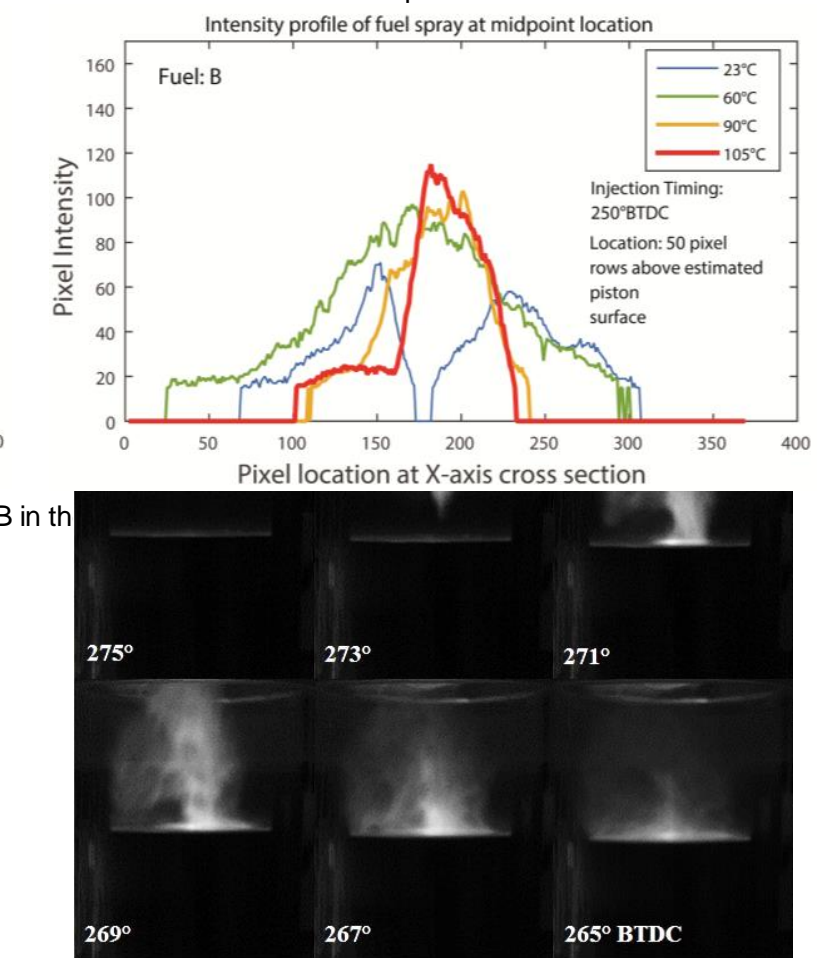

Dimensions: 384 x 448 pixels per image. Scale: $0.25 \mathrm{~mm}$ per pixel

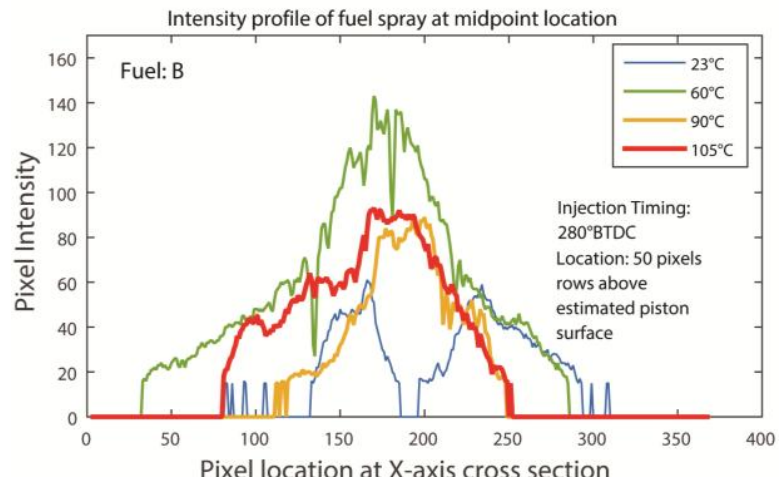

Figure 15. Example of spray distribution analysis of Fuel $B$ in the engine $w$ hen motoring $w$ ith $280^{\circ} B T D C$ injection timing. 


\section{PARTICULATE MEASUREMENTS RESULTS}

There were a total of 4 fuels tested in the single cylinder optical engine as described in the previous section. All of the fuels were tested for particulate matter emissions using the Cambustion DMS500, and engine data was also collected using a $L A B V I E W D A Q$ for further analysis. The engine was run at $\lambda=0.9$ to represent rich mixture excursions that have a large effect on the particulate matter emissions, and to represent stoichiometric combustion conditions $\lambda=1.01$ was used (so as to avoid inadvertently using mixtures rich of stoichiometric). The particulate matter results were filtered with a Wiebe function [25]. The filtered results have been shown to be comparable to those that would be obtained from a Particle Measurement Programme compliant Condensation Particle Counter system [10]. The Wiebe function is given by:

$$
\begin{gathered}
f=1-\exp \left[-3.54\left(\frac{d_{p}-14}{40}\right)^{1.09}\right]\left(d_{p} \geq 14\right) \\
f=0\left(d_{p}<14\right)
\end{gathered}
$$

where $d_{p}$ is the particulate diameter, in $\mathrm{nm}$.

\section{Fuel A}

Figures 16,17 and 18 show the particulate matter number and size distribution for the $A$ fuels $\left(A^{+}, A^{-}\right.$, A) tested in the engine. The engine was run with a standard injection timing of $280^{\circ} \mathrm{BTDC}$ which is a datum test point. Note that the experiments with the light fuels were conducted using the quartz annulus for combustion imaging. The results show that for the $A^{+}$and $A^{-}$fuels there are similar particulate spectra for all temperatures and lambda but with different magnitudes. It can be clearly seen that both Figures 16 and 17 show very low levels of particulates in the accumulation region (the nucleation mode had been removed by the Wiebe filter).

However, with the A fuel, which contains $40 \%$ by volume $n$-pentane and has volatility between $A^{+}$and $A^{-}$, there is an increased number of particulates in the accumulation region for the hottest fuel temperature as shown in Figure 18. This is possibly due to a trade-off between increased fuel penetration and piston impingement and the volatility of the fuel, since this is not seen with the more volatile Fuel $\mathrm{A}^{+}$which will have a greater penetration rate but also a faster fuel evaporation rate.

\section{Fuel B}

The next engine experiment conducted was with Fuel $\mathrm{B}$ and additional test parameters of injection timing: $250^{\circ} \mathrm{BTDC}, 280^{\circ} \mathrm{BTDC}$ and $310^{\circ} \mathrm{BTDC}$. The Page 14 of 18 engine was equipped with the full metal barrel construction solely to investigate the effect of aromatic addition in the fuel on the emission of particulate matter.

\section{Injection Timing $250^{\circ} \mathrm{BTDC}$}

It can be seen in Figure 19 that the particulate emissions are slightly higher at temperatures of $23^{\circ} \mathrm{C}$ and $60^{\circ} \mathrm{C}$ than at $90^{\circ} \mathrm{C}$ and $105^{\circ} \mathrm{C}$. The distribution of most particulates falls in the region between $14 \mathrm{~nm}$ and $100 \mathrm{~nm}$, having a peak value at $23.7 \mathrm{~nm}$. At this injection timing, the fuel had to evaporate faster in order to achieve a homogeneous mixture in the combustion chamber. At low temperatures, Fuel $B$ required more time to evaporate before being burned. This suggests that at this injection timing, the fuel evaporation rate has more influence than impingement severity because, although impingement was seen in the motoring experiments at this timing, the particulate number results at $90^{\circ} \mathrm{C}$ and $105^{\circ} \mathrm{C}$ fuel temperature were very low. At high temperatures, the vapour pressure of the fuel increases, so flash boiling occurs and accelerates evaporation and increases homogeneity even at the rich air/fuel ratio.

\section{Injection timing $280^{\circ} \mathrm{BTDC}$}

Particulate number emissions at a temperature of $60^{\circ} \mathrm{C}$ have a value close to those with the $250^{\circ} \mathrm{BTDC}$ injection timing, while at $23^{\circ} \mathrm{C}$ even for the rich mixture they dropped to the instrument noise level as shown in Figure 20. At temperatures of $90^{\circ} \mathrm{C}$ and $105^{\circ} \mathrm{C}$ however, unlike the $250^{\circ} \mathrm{BTDC}$ injection timing, particulate emissions were high and are an order of magnitude higher than at the lower temperatures. The particulate spectrum also changed slightly with the peak number concentration shifted to the region of 37 to $48 \mathrm{~nm}$. It was hypothesised that at this injection timing, the impingement of the fuel influences the development of particulate emissions rather than the reduced time for fuel evaporation. The fuel impinged more heavily (due to the closer proximity of the piston at this injection timing) but there was more time for evaporation as the fuel was injected $30^{\circ}$ crank angle earlier.

\section{Injection timing $310^{\circ} \mathrm{BTDC}$}

The particulates level at $310^{\circ}$ BTDC were very low and fell towards the level of the signal noise as shown in Figure 21. This was expected as the fuel was injected at an average cylinder pressure of 0.38 bar which caused an extreme level of flash boiling. Due to this, the fuel atomization was better; while a shorter droplet travel also reduced the potential droplet size build-up. There was also more time for the fuel to evaporate which in turn provides good homogeneity in the mixture. 


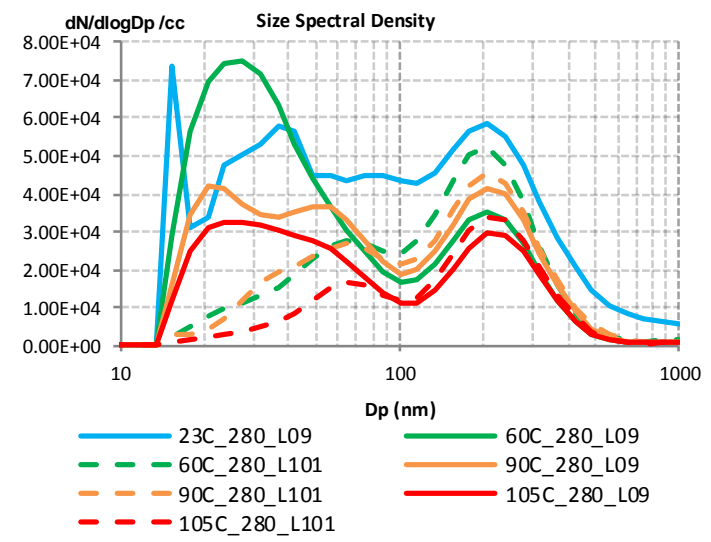

Figure 16. Wiebe filtered size distribution for Fuel $A^{-}$at various cylinder head temperatures with $\lambda$ of 0.9 (solid lines) and 1.01 (broken lines).

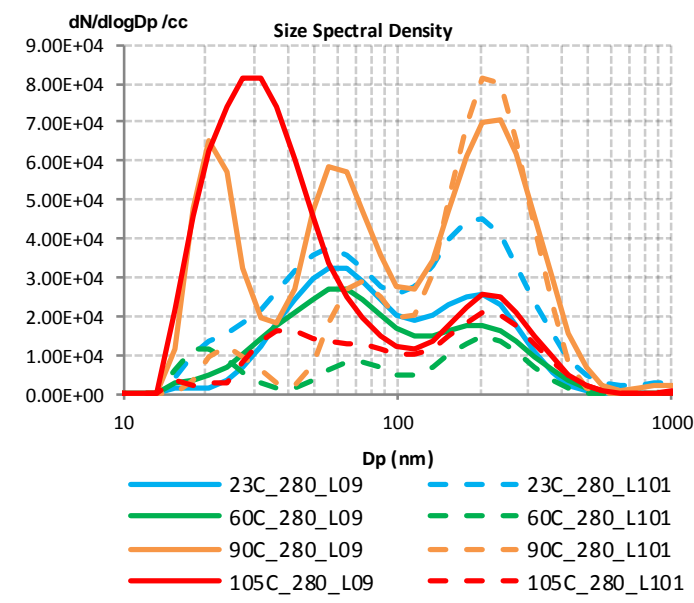

Figure 17. Wiebe filtered size distribution for Fuel $\mathrm{A}^{+}$at various cylinder head temperatures $w$ ith $\lambda$ of 0.9 (solid lines) and 1.01 (broken lines).

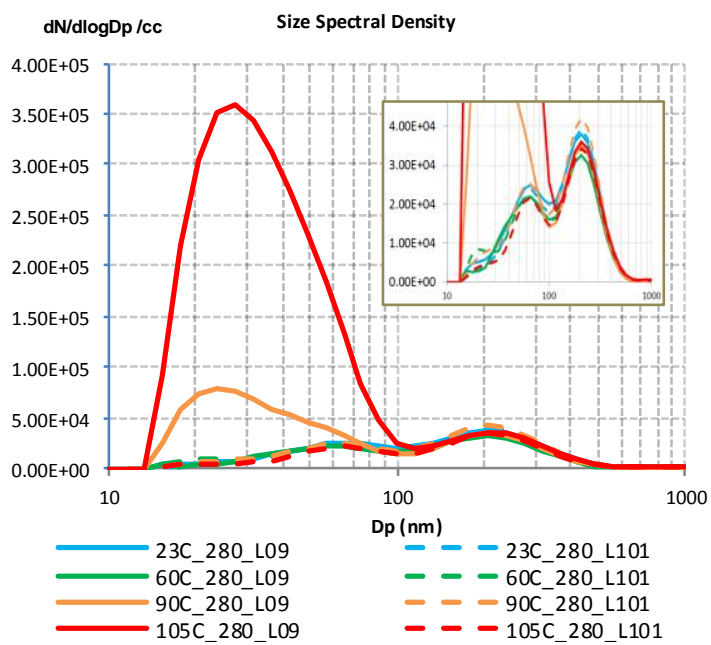

Figure 18. Wiebe filtered size distribution for Fuel $A$ at various cylinder head temperatures $w$ ith $\lambda$ of 0.9 (solid lines) and 1.01 (broken lines).

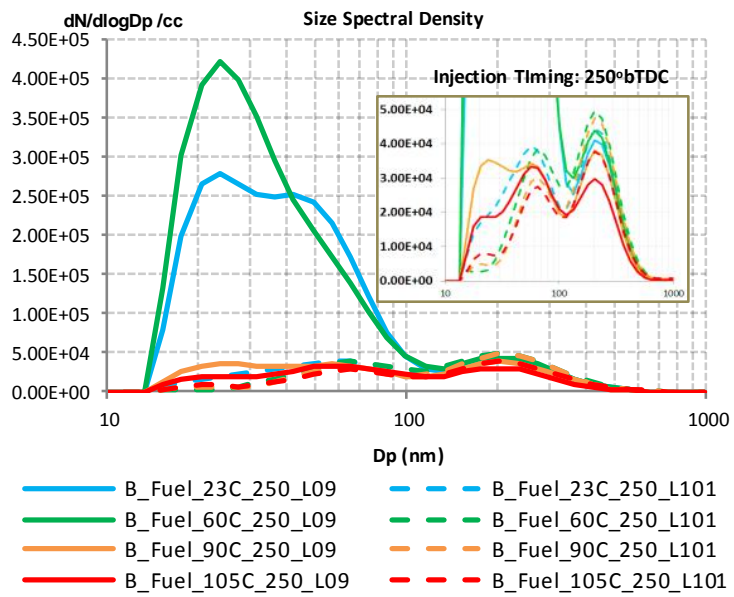

Figure 19. Wiebe filtered size distribution for Fuel $B$ at various cylinder head temperatures $w$ ith $\lambda$ of 0.9 (solid lines) and 1.01 (broken lines) and injection timing of $250^{\circ} \mathrm{BTDC}$

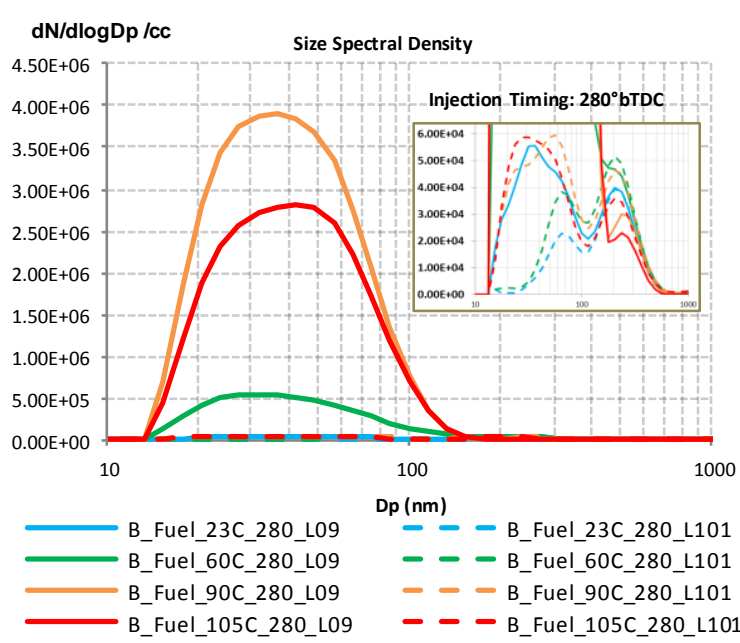

Figure 20. Wiebe filtered size distribution for Fuel B at various cylinder head temperatures with $\lambda$ of 0.9 (solid lines) and 1.01 (broken lines) and injection timing of $280^{\circ} \mathrm{BTDC}$ 


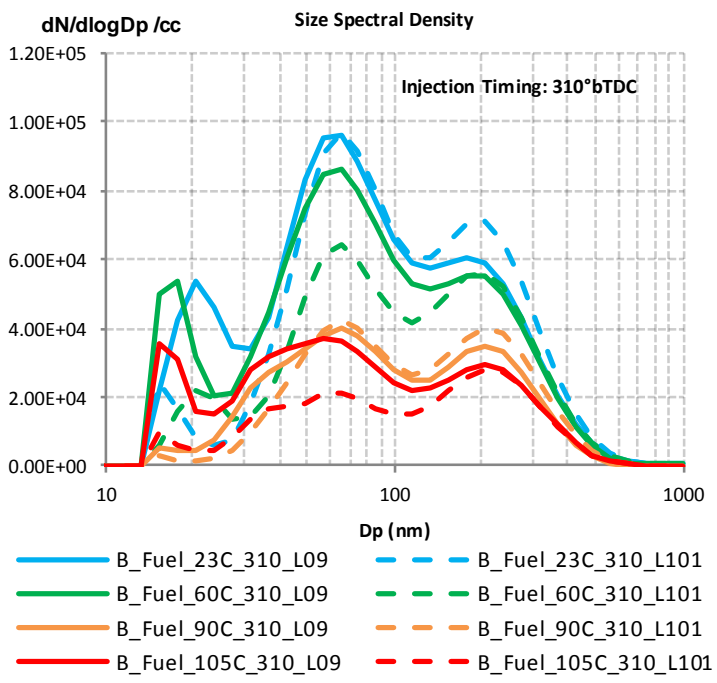

Figure 21. Wiebe filtered size distribution for Fuel B at various cylinder head temperatures with $\lambda$ of 0.9 (solid lines) and 1.01 (broken lines) and injection timing of $310^{\circ} \mathrm{BTDC}$

\section{DISCUSSION}

With the Fuel A blend, the particulate number results are low at the injection timing of $280^{\circ} \mathrm{BTDC}$, indicating that, despite the fuel impingement and local cooling from the methanol-containing fuel, there was adequate time and charge motion to evaporate the spray droplets and any fuel films to prevent excessive rich mixture combustion from occurring. This confirms that the absence of a heavy end to the fuel and the absence of aromatic content in the fuel will limit the particulate emissions at this low load condition. In particular, the Fuel $A^{-}$ (with $0 \%$ n-pentane), which had a higher initial boiling point than the $B$ fuel has a very low peak value of less than $1 \times 10^{5} \mathrm{dN} / \mathrm{dlogDp} / \mathrm{cc}$ at all conditions. The baseline Fuel A (with $40 \%$ npentane) did, however, produce greater particulate levels with the hottest fuel temperature as shown in Figure 18. Fuel $A$ has the intermediate volatility of $A, A^{+}$and $A^{-}$and, as is seen in Figure 9, has a similar degree of collapse at $105^{\circ} \mathrm{C}$ as the most volatile fuel, Fuel $\mathrm{A}^{+}$. This has led to a similarly large penetration at this condition. However, Fuel $A$ contains much more iso-octane than Fuel $\mathrm{A}^{+}$so subsequent evaporation of the droplets and any fuel films could be much slower. This may explain the higher particulate emissions at this condition. These levels are not seen with the least volatile fuel, Fuel $A^{-}$, despite its even higher iso-octane content, which could be explained by this fuel's reduced penetration and less extreme collapse at the highest temperature, which would act to reduce the severity of impingement or avoid it entirely. Therefore further tests would be required, perhaps to observe the sootformation during combustion, to investigate combustion phasing and variability or to check for impingement on intake valves or higher up the liner or other locations.
With the Fuel $B$ blend, the stoichiometric tests $(\lambda=$ 1.01) showed a similarly low level of particulates to the Fuel $A$ tests. However, during the rich tests $(\lambda=$ 0.9 ) the injection timing had a strong influence on the particulate emissions. With the injection timing at the datum of $280^{\circ}$ BTDC, the peak particulate emissions (at around 30-40 nm) tended to increase as the fuel temperature was increased, from levels similar to stoichiometric at $23^{\circ} \mathrm{C}$ to almost $4 \times 10^{6}$ $\mathrm{dN} / \mathrm{dlogDp} / \mathrm{cc}$ at $90^{\circ} \mathrm{C}$. This has implications for transient operations at this condition. The $90^{\circ} \mathrm{C}$ and $105^{\circ} \mathrm{C}$ fuel temperature engine tests can be compared with $120^{\circ} \mathrm{C}$ and $135^{\circ} \mathrm{C}$ fuel temperature spray rig tests respectively. In these, most of the spray was concentrated into a collapsed jet, which had a similar axial penetration to the sub-cooled spray but would lead to all sixplumes impinging in close succession, targeting onto a reduced area of the piston crown. It is anticipated that both the generation of fuel films on the piston crown and initial concentration of fuel vapour into a smaller volume of the cylinder would contribute to this worsening of the particulate emission at the hotter fuel temperature conditions.

Retarding the injection timing to $250^{\circ} \mathrm{BTDC}$ greatly reduced the emissions from the hot cases $\left(90^{\circ} \mathrm{C}\right.$ and $\left.105^{\circ} \mathrm{C}\right)$, had little effect on the emissions at $60^{\circ} \mathrm{C}$ and increased the cold emissions up to a level of $2.5 \times 10^{5} \mathrm{dN} / \mathrm{dlogDp} / \mathrm{cc}$. With the hottest fuel temperatures, the later injection will have reduced the intensity of impingement from the highly penetrating jet-like fuel sprays. Clearly there will be some kind of threshold between these two types of behaviour between $250^{\circ} \mathrm{BTDC}$ and $280^{\circ} \mathrm{BTDC}$, which will be important to understand in order to select appropriate injection timing. The increased emissions from the coldest fuel test reflects the reduced time available for evaporation and perhaps an increased level of impingement onto the liner has begun to create rich mixture combustion due to the formation of fuel films here.

The most interesting case is that of the very early injection at $310^{\circ} \mathrm{BTDC}$. This is only $25^{\circ}$ after the intake valves have opened and, as seen earlier, the cylinder pressure is low at this stage. In addition, the low valve lift will locally increase the incoming flow velocity in the spray near field. The greater degree of flash boiling coupled with the faster incylinder flow is thought to provide finer atomization of the fuel, which aids evaporation of the fuel and homogenization of the charge and is thought to contribute to the reduced particulate emissions at this injection timing - similar to levels seen with Fuel A. This is despite the intense early impingement of the spray onto the piston crown; it is also possible that the early fuel films developed on the piston crown are more rapidly evaporated due to the proximity to the faster air intake flow.

\section{CONCLUSIONS}

M15 gasoline fuels have been designed that independently vary volatility and also heavy 
component and aromatic content in order to understand the effect of the fuel composition on GDI fuel spray and subsequent particulate number emissions. Each fuel was imaged at a range of fuel temperatures in a sprayrig and in a motoring optical engine, from non-flashing sprays through transition to flare flashing sprays. The spray axial penetration and potential piston and liner impingement, and spray evaporation rate was extracted from the images. Firing engine tests with the fuels with the same fuel temperatures were performed and exhaust particulate number spectra captured using a Cambustion DMS500 Mark II particle spectrometer. Data from the spray images and knowledge of the fuel evaporative performance has been used to explain some of the observed findings.

In general, it has been found that use of an M15 fuel does not lead to consistently low levels of particulate number emissions across the range of injection timings and fuel temperatures examined. The fuel composition had a strong impact on whether there were significant particulate quantities in the exhaust, with the aromatic and low volatility content in Fuel B contributing to higher particulate emissions. However, the addition of the heavier components did not alter the spray structure under flash boiling conditions. The higher initial boiling point of Fuel $A^{-}$was not found to increase the quantity of particulate emissions, suggesting the light end of the gasoline mixture did not influence the creation of rich mixture conditions or liquid films, where particulates may be generated.

Varying fuel temperatures and system pressures led to different fuel saturation pressure to ambient pressure ratios. The inlet manifold pressure value may not give a good representation of the real incylinder pressure, as in this engine, only after $280^{\circ}$ BTDC was the cylinder pressure stabilized to a similar value to the inlet manifold pressure. An in depth knowledge of the in-cylinder pressure would give better information as to when specific fuels are best injected.

\section{CONTACT INFORMATION}

\author{
Richard Stone \\ Department of Engineering Science \\ University of Oxford \\ Parks Rd Oxford \\ OX1 3PJ \\ UK \\ richard.stone@eng.ox.ac.uk
}

\section{ACKNOWLEDGEMENTS}

Grateful thanks are extended to Jaguar Land Rover for the provision of the optical engine and financial support and for financial support from EPSRC (Awards EP/M009424/1 and 1182950).
The authors wish to acknowledge the support of the Malaysian Ministry of Higher Education and also the University of Oxford Clarendon Fund.

\section{REFERENCES}

1. EEA Report, 2014. Air quality in Europe: 2014 report,

2. Olah, G. a., Goeppert, A. \& Prakash, G.K.S., "Chemical recycling of carbon dioxide to methanol and dimethyl ether:From greenhouse gas to renewable, environmentally carbon neutral fuels and synthetic hydrocarbons". Journal of Organic Chemistry, 74(2), pp.487498, 2009, doi: 10.1021/j0801260f.

3. Trop, P., Anicic, B. \& Goricanec, D., "Production of methanol from a mixture of torrefied biomass and coal". Energy, 77, pp.125-132, 2014. doi: 10.1016/j.energy.2014.05.045.

4. Braisher, M., Stone, R., and Price, P., "Particle Number Emissions from a Range of European Vehicles," SAE Technical Paper 2010-01-0786, 2010, doi:10.4271/2010-01-0786

5. Piock, W., Hoffmann, G., Berndorfer, A., Salemi, P. et al., "Strategies Towards Meeting Future Particulate Matter Emission Requirements in Homogeneous Gasoline Direct Injection Engines," SAE Int. J. Engines 4(1):1455-1468, 2011, doi:10.4271/2011-011212

6. Whitaker, P., Kapus, P., Ogris, M., and Hollerer, P., "Measures to Reduce Particulate Emissions from Gasoline DI engines," SAE Int. J. Engines 4(1):1498-1512, 2011, doi:10.4271/2011-01-1219

7. Steeper, R. and Stevens, E., "Characterization of Combustion, Piston Temperatures, Fuel Sprays, and Fuel-Air Mixing in a DISI Optical Engine," SAE Technical Paper 2000-01-2900, 2000, doi:10.4271/2000-01-2900

8. Ketterer, J. and Cheng, W., "On the Nature of Particulate Emissions from DISI Engines at Cold-Fast-Idle," SAE Int. J. Engines 7(2):986994, 2014, doi:10.4271/2014-01-1368

9. Sobotowski, R., Butler, A., and Guerra, Z., "A Pilot Study of Fuel Impacts on PM Emissions from Light-Duty Gasoline Vehicles," SAE Int. J. Fuels Lubr. 8(1):214-233, 2015, doi:10.4271/2015-01-9071

10. Leach, F., Stone, R., and Richardson, D., "The Influence of Fuel Properties on Particulate Number Emissions from a Direct Injection Spark Ignition Engine," SAE Technical Paper 2013-01-1558, 2013, doi:10.4271/2013-011558.

11. Vuk, C. and Vander Griend, S., "Fuel Property Effects on Particulates In Spark Ignition Engines," SAE Technical Paper 2013-01-1124, 2013, doi:10.4271/2013-01-1124.

12. Karavalakis, G., Short, D., Vu, D., Russell, R.L., Asa-Awuku, A., Jung, H., Johnson, K.C. \& Durbin, T.D.,"The impact of ethanol and isobutanol blends on gaseous and particulate emissions from two passenger cars equipped with spray-guided and wall-guided direct 
injection SI (spark ignition) engines." Energy, 82, pp.168-179, 2015, doi: 10.1016/j.energy.2015.01.023

13. Price, P., Twiney, B., Stone, R., Kar, K. et al., "Particulate and Hydrocarbon Emissions from a Spray Guided Direct Injection Spark Ignition Engine with Oxygenate Fuel Blends," SAE Technical Paper 2007-01-0472, 2007, doi:10.4271/2007-01-0472،

14. M., Mojtabi, N., Chadwick, G., Wigley, J., Helie, "The Effect of Flash Boiling On Break Up and Atomization in GDI Sprays" presented at ILASS 2008: $22^{\text {nd }}$ European Conference on Liquid Atom mization and Spray Systems, Como Lake, Italy, September 2008

15. Dahlander, P., Lindgren, R., Denbratt, L., "High-Speed Photography And Phase Doppler Anemometry Measurements of Flash-Boiling Multi-Hole Injector Sprays for Spray-Guided Gasoline Direct Injection" presented at ICLASS 2006: $10^{\text {th }}$ International Conference on Liquid Atomization and Spray Systems, Kyoto, Japan, September, 2006

16. Xu, M., Zhang, Y., Zeng, W., Zhang, G. et al., "Flash Boiling: Easy and Better Way to Generate Ideal Sprays than the High Injection Pressure," SAE Int. J. Fuels Lubr. 6(1):137148, 2013, doi:10.4271/2013-01-1614

17. Zeng, W., Xu, M., Zhang, G., Zhang, Y. \& Cleary, D.J., "Atomization and vaporization for flash-boiling multi-hole sprays with alcohol fuels". Fuel: 287-297, 2012, doi: 10.1016/j.fuel.2011.08.048

18. Liu, S., Cuty Clemente, E.R., Hu, T. \& Wei, Y., "Study of spark ignition engine fueled with methanol/gasoline fuel blends." Applied Thermal Engineering, 27(11-12), pp.19041910, 2007.2 doi: 10.1016/j.applthermaleng.2006.12.024

19. Wang, X., Ge, Y., Liu, L., and Gong, H., "Regulated, Carbonyl Emissions and
Particulate Matter from a Dual-Fuel Passenger Car Burning Neat Methanol and Gasoline," SAE Technical Paper 2015-01-1082, 2015, doi:10.4271/2015-01-1082

20. Liang, B., Ge, Y., Tan, J., Han, X., Gao, L., Hao, L., Ye, W. \& Dai, P.,"Comparison of PM emissions from a gasoline direct injected (GDI) vehicle and a port fuel injected (PFI) vehicle measured by electrical low pressure impactor (ELPI) with two fuels: Gasoline and M15 methanol gasoline." Journal of Aerosol Science: Volume 57, pp.22-31,2013. doi: 10.1016/j.jaerosci.2012.11.008

21. Geng, P., Zhang, H. \& Yang, S.,"Experimental investigation on the combustion and particulate matter (PM) emissions from a port-fuel injection (PFI) gasoline engine fueled with methanolultralow sulfur gasoline blends," Fuel: Volume 145, pp.221-227, $2015 . \quad$ doi: 10.1016/j.fuel.2014.12.067

22. BS EN 228:2012 Automotive fuels - Unleaded petrol - Requirements and test methods

23. Camm, J., Stone, R., Davy, M., and Richardson, D., "The Effect of Non-Ideal Vapour-Liquid Equilibrium and Non-Ideal Liquid Diffusion on Multi-Component Droplet Evaporation for Gasoline Direct Injection Engines,"SAE Technical Paper 2015-01-0924, 2015, doi:10.4271/2015-01-0924.

24. Hung, D.L.S., Harrington, D.L., Gandhi, A.H., Markle, L.E., Parrish, S.E., Shakal, J.S., Sayar, H., Cummings, S.D. \& Kramer, J.L., 2008. Gasoline Fuel Injector Spray Measurement and Characterization - A New SAE J2715 Recommended Practice. SAE International Journal of Fuels and Lubricants, 1(1), pp.200801-1068.

25. M. Braisher, "Particulate Matter Emissions Measurements from Engines and Vehicles", D.Phil. thesis, University of Oxford, 2010. 